\title{
EU ETS Facets in the Net: Structure and Evolution of the EU ETS Network
}

\author{
Simone Borghesi, Andrea Flori ${ }^{\dagger}$
}

19-August-2018

Keywords: Emission Trading, EU ETS, European Union Transaction Log (EUTL) data, Account and Transaction Types, Network Analysis, Centrality Measures

JEL Codes: D85, L14, Q48, Q54, Q58

\begin{abstract}
In this work, we investigate which countries have been more central during Phases I and II of the European Emission Trading Scheme (EU ETS) with respect to the different types of accounts operating in the system. We borrow a set of centrality measures from Network Theory's tools to describe how the structure of the system has evolved over time and to identify which countries have been in the core or in the periphery of the network. Performing partitions on the different types of accounts and transactions characterizing the EU ETS, we investigate whether intermediaries have affected the overall structure of the system. From the analysis of the European Union Transaction Log data over the period 2005-2012, we find that some national registries (France, Denmark, Germany, United Kingdom, The Netherlands) were much more central than others in the network. Empirical evidence, moreover, shows that some account holders strategically opened additional accounts in the more central registries, thus reinforcing their centrality in the network. Finally, it turns out that Person Holding Accounts (PHAs) have played a prominent role in the transaction of permits, heavily influencing the configuration of the system. This motivates further research on the impact of non-regulated entities in the EU ETS design.
\end{abstract}

\section{Introduction}

In the last decade, the European Emission Trading Scheme (henceforth EU ETS) has been the object of much attention among scholars and policy-makers. Introduced in January 2005, the EU ETS covers 31 countries and more than 11,000 installations from several emission-intensive industry, which account for about $50 \%$ of the total European CO2 emissions, and $45 \%$ of all GHG emissions. The EU ETS was originally divided in three different phases of increasing length: (i) Phase I: 2005-2007, which was conceived as a learning phase, (ii) Phase II: 2008-2012 and (iii) Phase III: 2013-2020. In addition, a new Directive reforming the EU ETS for Phase IV (2021-2030) has recently been adopted (European Parliament and Council of the European Union, 2018).

Since its implementation in 2005, the EU ETS has attracted particular interest for its impressive dimension and record features, being the first transboundary cap-and-trade scheme and the world's largest ETS (at least until the newly born Chinese national ETS to be implemented in 2017). In this sense, as argued by Ellerman et al. (2010), the EU ETS can be conceived as the prototype for similar ETS regimes that have been subsequently established in other regions (California, the Regional Greenhouse Gas Initiative introduced in the Western part of the US, Alberta and Quebec in Canada, China, South Korea, Japan, Kazakhstan) and are rapidly spreading worldwide with new emerging schemes projected in many countries (World Bank, 2014).

The literature on the EU ETS has been growing very rapidly over the years. As in the literature review by Martin et al. (2016), much of the literature has looked at the effects of the EU ETS on three different but related aspects: (i) emission abatement (Ellerman and Buchner, 2008; Ellerman et al., 2010; Anderson and Di Maria, 2011; Bel and Joseph, 2015), (ii) economic performance and competitiveness, (Abrell et al., 2011; Fabra and Reguant, 2014; Martin et al., 2014a,b), and (iii) innovation (see Hoffmann, 2007; Aghion et al., 2009; Rogge et al., 2011; Schmidt et al., 2012; Martin et al., 2013; Borghesi et al., 2015; Calel and Dechezlepretre, 2016).

Other studies have devoted particular attention to specific aspects or problems encountered by the EU ETS during its implementation, such as the over-allocation registered in the early phases (Sijm, 2005), the causes, components and consequences of the observed price volatility (Alberola et al., 2008; Chevallier, 2011; Medina et al., 2014; Gronwald and Hintermann, 2015), the drivers of the price fall in Phase II (Koch et al., 2014), the existence of frauds and monitoring problems (Frunza et al., 2011). These problems have generated

*European University Institute and University of Siena, Italy, simone.borghesi@eui.eu. (Corresponding author)

${ }^{\dagger}$ Politecnico di Milano, Department of Management, Economics and Industrial Engineering andrea.flori@polimi.it 
a heated debate on the limitations of the EU ETS, which eventually led the European Commission to propose structural measures to reform the EU ETS (De Perthuis and Trotignon, 2014; Edenhofer et al., 2014). ${ }^{1}$

Finally, the rapid extension of ETSs outside the EU ETS has spurred a new research line concerning the perspective of linking the EU ETS with other similar ETSs around the world (Anger, 2008; Tuerk et al., 2009; Borghesi et al., 2016; Ranson and Stavins, 2016; Doda and Taschini, 2017).

Despite the vast and ever growing literature on the EU ETS, however, little attention has been paid to the market structure that emerges from the relationships underlying the EU ETS. Very few studies (Jaraite et al., 2013a,b; Betz and Schmidt, 2016; Fan et al., 2016; Liu et al., 2017) have performed a detailed analysis of the European data set on the transactions occurring in the EU ETS in order to identify the agents involved in the transactions, their country location, the type of transactions being concluded, the direction of the flows, etc.

Among them, Jaraite et al. (2013a,b) provide a detailed description of the ownership situation in the EU ETS in Phase I by mapping individual EU ETS accounts to their Global Ultimate Owner (GUO), that is, to the parent company that owns the accounts. In particular, they focus their analysis on two main types of accounts: Operator Holding Accounts (OHA) that are associated in a 1:1 relationship to each installation regulated under the EU ETS, and Personal Holding Accounts (PHA) that are voluntary accounts used for emission trading by unregulated firms. One account holder can control several OHAs and PHAs in the EU ETS. Moreover, a single parent company can control in turn several account holders. Therefore, by tracing back to the GUO, the analysis performed by the authors helps provide the general framework of the final actors actually involved in the EU ETS market during Phase I.

Betz and Schmidt (2016) investigate the transfer patterns that emerged in the European carbon market during Phase I of the EU ETS. Using cluster analysis, the authors find that most installations regulated by the EU ETS are not or hardly participating in the market; only a small subset of market participants are very active in the EU ETS and they mainly belong to non-regulated companies (e.g. banks). This confirms preliminary results of early studies based on surveys that emphasized the limited participation to the market (Löschel et al., 2010 and 2011), as well as the initial lack of knowledge of the ETS and its functioning by many regulated companies and the prominent role of the financial sector in acting as "arbitrageur" ${ }^{2}$ (Pinkse and Kolk, 2007; Engels et al., 2008).

Fan et al. (2016) analyse how the micro-behavior of emitting companies and financial intermediaries has affected the carbon price in the EU ETS. Using CITL data over the period 2005-08, the authors distinguish between compliance and non-compliance trading of the emitting companies according to the underlying trading motivations and find that compliance trading is positively related to the carbon price mean value, while non-compliance trading affects its volatility.

Using data on the first two phases of the EU ETS, Liu et al. (2017) present a micro-study that investigates the trading performance of the emitting companies, measured in terms of their capacity to increase profits and/or save costs in emission trading. Building on a series of monetary and behavioral variables, the authors find that the trading performance of emitting companies is affected by emissions level, industrial sector and trading requirement. More precisely, their results suggest that regulated companies with lower emissions level had a better trading performance than more polluting companies; it follows that the manufacturing sector (that has a higher share of less polluting companies) outperformed the energy sector.

The small number of studies in the literature examining the EU ETS transactions and structure is probably due to the very nature of the data set and to the delay with which data have been released in the past. Today, however, there exist sufficient data to perform an investigation of the ETS structure which may provide interesting insights on the features of the system and on the possible implications concerning its functioning. For this reason, using a longer data set than the one adopted in most previous studies, the present paper intends to examine the evolution that the structure of the EU ETS transactions has had over time. More precisely, building on the evidence concerning the crucial role of intermediaries in the EU ETS that emerged from previous studies, we aim to evaluate here how non-regulated entities may have affected the network of the EU ETS transactions. As Betz and Schmidt (2016) have argued, moreover, companies may have strategically chosen the countries in which to open a PHA, so that an account can be opened in a registry that differs from the country of origin of the account holder. For this reason, it seems particularly important to identify the country/registry of origin and destination of the transfer patterns being observed, an aspect that has been mainly overlooked in the literature so far. To fill this gap in the extant literature, the present study proposes for the first time a network theory approach to represent the system at the national registry level. This will allow us to identify: (i) which registries have been more active in the first two phases of the EU ETS, playing a central role in the EU ETS network, (ii) which registries have been more appealing for those that decided to open an account abroad and (iii) where the latter come from, namely, the country of origin of the moving accounts.

\footnotetext{
${ }^{1}$ See Hepburn et al. (2016) and the special issue on "The economics of the EU ETS market stability reserve" for a discussion of the critiques moved to the EU ETS due to low carbon prices and large surplus of allowances, and an evaluation of the reform proposals. In this regard, see also Kollenberg and Taschini (2016) for the proposal of an automatic cap adjustment mechanism that may avoid the limited flexibility of the market stability reserve mechanism, and Koch et al. (2016) on market responses to political cap adjustments.

${ }^{2}$ A similar issue was examined also by Trotignon and Delbosc (2008) that provided the very first study based on the EU Community Independent Transaction Log (CITL). The authors point out that the most active players in the market belong to the electricity sector. However, no installation-specific transaction data were available at that time, thus inevitably limiting the scope of their analysis.
} 
One of main advantages of representing the EU ETS as a network relies on the exploitation of centrality measures, based on the structure of the system, to investigate the role played by EU ETS Member States. This can provide an innovative perspective on the EU ETS that allows also to get a deeper insight not only on the trading behaviour of non-regulated participants but also on the role that single Member States may have played within the EU ETS. In our view, moreover, identifying the entity and the direction of the moving accounts can provide useful information that may help policy-makers understand which national registries look more attractive for the agents and improve the design of the EU ETS in the future. For instance, by performing network analysis in real time and observing changes in the structure of the system, policy-makers could detect the presence of outliers that is not revealed by other monitoring instruments, or the emergence of atypical behaviors that may deserve further analyses or specific regulations. Finally, the network representation of the cross-border linkages can also shed light on the interdependence across countries, which could provide a useful tool to perform risk assessment in the future ${ }^{3}$.

The present work differs from the few existing studies mentioned above that examine the European data set in several respects. In the first place, all previous contributions (except Liu et al. (2017) who examine, however, a different issue) focused only on Phase I (the so-called learning phase) of the EU ETS, whereas the present study extends the analysis to a longer period (2005-2012) encompassing both Phase I and Phase II. In the second place, while previous studies (Jaraite et al. (2013a,b); Betz and Schmidt, 2016; Fan et al., 2016; Liu et al., 2017) focused on the account level that is then aggregated at the parent company level, this work focuses on national registries to assess how Member States are connected in the EU ETS and which countries played a central role in the system in the first two phases. This leads to a third main distinction with respect to the rest of the literature: differently from other studies we take into account a wider set of transactions, including -among the others- those types of transactions (Allowance Allocation, Allowance Surrender etc...) that involve a government holding account through which allowances are issued and surrendered. Finally, using network theory instruments, the present study is the first to compare the configuration emerging at registry-level with the one at country-level: as mentioned above, this allows to identify and quantify the observed shift of some account holders from their country of origin towards other (presumably more favorable) national registries.

To examine the issues discussed above the structure of the paper will be as follows. Section 2 describes the data set used in the work. Section 3 focuses on the methodology adopted in the analysis, devoting particular attention to the network measures taken into account. Section 4 discusses the main results emerging from the analysis. Section 5 contains some concluding remarks.

\section{Data Description}

Our data set is drawn from the European Union Transaction Log (hereinafter EUTL) and covers transactions occurred between February 2005 and December 2012, thus encompassing both Phase I and Phase II. This sample includes ${ }^{4}$ i) the time and the type of each transaction, ii) the administrative national registry, the account type and the identity of each counterpart, and iii) the number of transferred units. Transactions refer to the physical transfer of allowances in the spot markets and their delivery in the futures markets, while the EUTL does not report the corresponding trading prices paid for the transfers ${ }^{5}$.

As known from the literature (see for instance Cló, 2009; Laing et al., 2014), European countries joined the program at different times, although most of them entered the EU ETS between 2005 and $2006^{6}$. Data from the beginning of Phase II include also transactions from and to non-EU countries (e.g. Australia, Japan, New Zealand and the Russian Federation) as well as the use of credits from both the Clean Development Mechanism (CDM) and the Joint Implementation (JI) projects.

\footnotetext{
${ }^{3}$ A similar network analysis has been recently performed by the European System Risk Board to measure systemic risk in the EU financial system: https://www.esrb.europa.eu/pub/rd/html/index.en.html.

${ }^{4}$ Data are retrieved from: http://ec.europa.eu/environment/ets/transaction.do. EUTL replaced the Community Independent Transaction Log (CITL) which regulated transactions across national registries before the Union registry was established in mid2012. Basically a registry is an electronic platform which keeps track of allowances' holdings and transfers by individuals, installations or states which hold accounts within the registry. The Union registry is established pursuant to the Directive 2003/87/EC amended in 2009. The EUTL website provides several data sets, including not only transactions but also the allocations to stationary installations, compliance data and detailed information on the accounts profiles. For a description of how these tables can be mapped between each other see e.g. Jaraitè et al. (2013b) and Liu et al. (2017).

${ }^{5}$ Trading information can be deduced from the serial numbers of the transferred permits. Market participants can trade in the form of spot contracts, futures or forwards instruments, swaps and options on futures. BlueNext (France) was the most active exchange platform for spot contracts during Phase I. Futures accounted for the bulk of transactions (World Bank, 2010), although delivered futures represented less than $14 \%$ in Phase I (Fan et al., 2016). Phase II was deeply influenced by futures markets which represented about $80 \%$ of the transactions in 2012 (Ellerman, et al., 2016). Central trading platforms for futures and options were the European Climate Exchange (ECX) and the Intercontinental Exchange (ICE). Other relevant platforms for trading in EU ETS instruments were: NordPool in Oslo, the European Energy Exchange (EEX) in Leipzig, and the New York Mercantile Exchange (NYMEX) based in US. Notwithstanding the presence of devoted exchange platforms, the share of OTC transactions was remarkable in both Phases (World Bank, 2011).

${ }^{6}$ EU ETS included all $25 \mathrm{EU}$ Member States in Phase I, growing to 27 members once Romania and Bulgaria joined the EU in 2007. Phase II included also Norway, Iceland and Liechtenstein.
} 


\subsection{Transaction Types}

The distribution of the different types of transactions involved in the EU ETS is shown in Table 1. There are two main partitions that relate to our study: internal transactions (i.e. within the same national registry, code 10), and external transactions (i.e. between national registries, code 3 ).

Table 1 exhibits a variety of transaction types summarized by both the number of transactions and the amount of traded units ${ }^{7}$. Internal transactions include a wide set of different sub-categories. Among these, Internal Transfer (10-0), Allowance Surrender (10-2) and Allowance Allocation (10-53) are the types more common in terms of number of transactions, while the other categories are residual. Results are quite comparable when we consider the number of transferred units, although in this case also code 10-52 (Allowance issue, 2008-2012 onwards) and code 10-61 (Surrendered Allowance Conversion) become relevant. As to the external transactions (code 3), they are divided in three main categories: code 3-21 refers to External Transfer over the period 2005-2007 (Phase I), while code 3-0 stands for transactions in subsequent years, and code 3-2 refers to Allowance Surrender.

Table 1: Transaction Types. First column provides the description of each transaction type. Codes in the second column represent the transaction types: those starting with 10 refer to internal transactions, while those starting with 3 indicate external transactions between registries. The number on the left of the dash indicates the Kyoto transaction type, while that on the right provides the supplementary information needed to distinguish the type of transaction. The third column shows the number of transactions for each type, while the last column refers to the amount of transferred units. Source: authors' own elaborations based on the EUTL transactions data set for the first two Phases.

\begin{tabular}{|c|c|c|c|}
\hline Explanation & Transaction Type & \# of Transactions & \# of Units \\
\hline Issuance - Initial creation of a unit & $1-0$ & 46 & $27,921,646,859$ \\
\hline Issuance - External transfer between Art. 63 a registries & $1-22$ & 2 & $36,964,946$ \\
\hline Issuance - Internal transfer Art. $63 a$ & $1-24$ & 4 & $1,011,231$ \\
\hline Issuance - Aviation allowances & $1-30$ & 40 & $50,121,034$ \\
\hline Issuance - General allowances & $1-31$ & 2 & $300,000,000$ \\
\hline Issuance - Allowance issue (2005-2007) & $1-51$ & 227 & $6,538,641,646$ \\
\hline Conversion - Transformation of unit to create an ERU & $2-0$ & 732 & $71,145,927$ \\
\hline External Transfer & $3-0$ & 139,966 & $13,887,754,931$ \\
\hline External Transfer - Allowance surrender & $3-2$ & 117 & $25,424,725$ \\
\hline External Transfer (2005-2007) & $3-21$ & 15,472 & $1,009,787,726$ \\
\hline Cancellation - Internal transfer of unit & $4-0$ & 1,580 & $59,714,321$ \\
\hline Cancellation - External transfer between Art. 63 a registries & 4-22 & 2 & $14,550,908$ \\
\hline Cancellation - Conversion of Art. 63 a allowances & $4-26$ & 20 & 508,510 \\
\hline Cancellation - Retirement (2005-2007) & $4-3$ & 77 & $5,956,279,442$ \\
\hline Retirement - Internal transfer of unit & $5-0$ & 43 & $1,167,180,428$ \\
\hline Retirement - Allowance cancellation (2005-2007) & $5-1$ & 196 & $7,252,605,015$ \\
\hline Internal Transfer & $10-0$ & 325,368 & $42,560,619,951$ \\
\hline Internal Transfer - Allowance Cancellation (2005-2007) & 10-1 & 3,286 & $76,877,305$ \\
\hline Internal Transfer - Allowance Surrender & $10-2$ & 85,837 & $14,038,141,353$ \\
\hline Internal Transfer - Issuance/Internal Transfer Art $63 a$ & $10-24$ & 4 & $1,011,231$ \\
\hline Internal Transfer - Conversion of Art. 63 a Allowances & $10-26$ & 20 & 508,510 \\
\hline Internal Transfer - Allocation of Aviation Allowances & 10-35 & 342 & $146,831,820$ \\
\hline Internal Transfer - Allocation of General Allowances & $10-36$ & 291 & $32,173,776$ \\
\hline Internal Transfer - Auction Delivery & 10-37 & 24 & $92,201,500$ \\
\hline Internal Transfer - Cancellation and Replacement & $10-41$ & 20 & $272,312,173$ \\
\hline Internal Transfer - Allowance Issue (2008-2012 onwards) & 10-52 & 273 & $10,988,834,103$ \\
\hline Internal Transfer - Allowance Allocation & $10-53$ & 82,376 & $16,261,299,127$ \\
\hline Internal Transfer - Correction to Allowances & $10-55$ & 8 & $4,114,611$ \\
\hline Internal Transfer - Surrendered Allowance Conversion & 10-61 & 164 & $6,851,333,407$ \\
\hline Internal Transfer - Deletion of Allowances & $10-90$ & 14 & $174,319,601$ \\
\hline Internal Transfer - Reversal of Allowance Surrender & 10-92 & 130 & $19,493,569$ \\
\hline Internal Transfer - Correction & 10-93 & 51 & $1,316,081$ \\
\hline \multirow[t]{2}{*}{ Internal Transfer - Reversal of Allowance Cancellation } & $10-104$ & 1 & $9,169,982$ \\
\hline & Total & 656,735 & $155,823,895,749$ \\
\hline Issuance & code 1 & 321 & $34,848,385,716$ \\
\hline Conversion & code 2 & 732 & $71,145,927$ \\
\hline External Transfer & code 3 & 155,555 & $14,922,967,382$ \\
\hline Cancellation & code 4 & 1,679 & $6,031,053,181$ \\
\hline Retirement & code 5 & 239 & $8,419,785,443$ \\
\hline Internal Transfer & code 10 & 498,209 & $91,530,558,100$ \\
\hline
\end{tabular}

\footnotetext{
${ }^{7}$ In addition to internal and external transactions the other types refer to: Issuance - initial creation of a unit (code 1 ); Conversion - transformation of unit to create an ERU (code 2); Cancellation - internal transfer of unit (code 4); Retirement internal transfer of unit (code 5). Following Betz and Schmidt (2016), we refer to: Issuance when assigned units (AAUs) from Party Holding Accounts are converted into European Union Allowances (EUAs); Allocation when EUAs are allocated to regulated entities (OHAs); Surrendering when OHAs return EUAs to the Party Holding Account for compliance purposes; Retirement when the corresponding units are transferred into the Party Retirement Account to fulfill Kyoto Protocol obligations against the reported emissions of that Party; Cancellation and Replacement when EUAs are switched from one period into the next compliance period. As Fan et al. (2016) pointed out, circulation of the different types of allowances sum up to zero in a national registry; moreover, net external positions (buying/selling across registries) and residual for non regulated entities balance out within the EU perimeter. See the EUTL data set for a detailed description of each transaction type.
} 
We notice that internal transactions were much more frequent than external ones during the observed period, in terms of both number of transactions (column 2) and number of transferred units (column 3). This points to the preference for domestic transactions and the presence of a certain level of stickiness in the way participants trade across national borders, which is already informative for the structure of the EU ETS. External transactions, however, represented a relevant share of total internal and external transactions (sum of codes 3 and 10), being equal to 23.79 per cent of the number of transactions and 14.02 per cent of their overall volume.

Finally, we note that the compliance process (e.g., codes 10-2 and 10-53) absorbs as expected a large share of transactions. As will be discussed in Section 3, the core of our study refers to pure transactions (codes 3-0, 3-21, and 10-0) which involve both internal and external transfers excluding the main administrative transactions with a state counterpart (e.g. allowances issuance, allocation or surrender).

\subsection{Account Types}

The presence of specific account types relates to the different transaction types as seen in subsection 2.1. We refer to the account types reported in the EUTL transactions ${ }^{8}$ data set to distinguish among the participants trading in the EU ETS.

In particular, Table 2 exhibits both the number of transactions and the amount of transferred units between different types of transferring and acquiring accounts during the first two Phases, identified by rows and columns codes, respectively. They include the Holding Account (HA, code 100), the Pending Account (PA, code 110), the Operator Holding Account (OHA, code 120) and the Person Holding Account (PHA, code 121). In addition, in Table 2 code $N A$ stands for not completely available account type information, while codes 210, 230 and 300 refer to the Net Source Cancellation Account, the Voluntary Cancellation Account and the Retirement Account, respectively.

Table 2: Transactions Summary Statistics for different Account Types. Codes stand for: Holding Account (HA-100), Pending Account (PA-110), Operator Holding Account (OHA-120), Person Holding Account (PHA-121), Net Source Cancellation Account (CA-210), Voluntary Cancellation Account (VCA-230), Retirement Account (RA-300), and accounts for which account type information presents missing values (NA). Row codes stand for transferring accounts (T), column codes refer to acquiring accounts (A). The first panel stands for the number of transactions, while the second panel shows the amount of transferred units. Source: authors' own elaborations based on the EUTL transactions data set for the first two Phases.

\begin{tabular}{|c|c|c|c|c|c|c|c|c|}
\hline Account Type $(\mathbf{T} \backslash \mathbf{A})$ & HA (100) & OHA (120) & PHA (121) & CA $(210)$ & $\operatorname{VCA}(230)$ & RA (300) & NA & Total \\
\hline HA (100) & 25,747 & 50,464 & 9,573 & 10 & 114 & 293 & 39.503 & 125,704 \\
\hline OHA $(120)$ & 74,994 & 15,114 & 38,924 & 0 & 2,191 & 0 & 26,172 & 157,395 \\
\hline PHA (121) & 6,379 & 27,442 & 295,548 & 0 & 2,299 & 0 & 31,736 & 363,404 \\
\hline NA & 144 & 4 & 0 & 0 & 0 & 0 & 4,318 & 4,466 \\
\hline Total & 107,859 & 93,521 & 348,719 & 10 & 4,604 & 293 & 101,729 & 656,735 \\
\hline PA (110) & $28,279,099$ & $3,696,620$ & $490,616,768$ & 0 & 0 & 0 & 0 & $522,592,487$ \\
\hline OHA $(120)$ & $11,552,181,241$ & $970,182,228$ & $2,659,514,104$ & 0 & $59,985,108$ & 0 & $3,584,166,021$ & $18,826,028,702$ \\
\hline PHA (121) & $1,014,335,778$ & $2,330,851,154$ & $18,725,422,161$ & 0 & $17,151,313$ & 0 & $5,497,972,536$ & $27,585,732,942$ \\
\hline $\operatorname{VCA}(230)$ & $9,169,982$ & 0 & 0 & 0 & 0 & 0 & 0 & $9,169,982$ \\
\hline NA & $24,684,847,820$ & $1,011,231$ & 0 & 0 & 0 & 0 & $6,408,068,708$ & $31,093,927,759$ \\
\hline Total & $75,685,292,451$ & $12,789,484,347$ & $23,506,873,567$ & $22,347,707$ & $126,657,242$ & $12,995,851,542$ & $30,697,388,893$ & $155,823,895,749$ \\
\hline
\end{tabular}

OHAs refer to accounts used for trading and compliance purposes which are held by operators of installations (regulated entities) covered by EU ETS. Each installation is associated with an OHA and many operators can be related to the same parent company. As shown in Table 2, OHAs are more likely to trade with the other account types: only 2.3 per cent of the transactions involve OHAs as both counterparts $(0.62$ per cent in terms of overall volume). Their total amount of transferred units $(18,826,028,702)$ is higher than the sum of acquired units $(12,789,484,347)$. This suggests their role as net suppliers in the system.

PHAs instead represent voluntary trading accounts, which can belong to a common parent company similarly to OHAs. About 45 per cent of the overall transactions is within the PHAs perimeter (12.02 per cent in terms of volumes). This stresses their active role in the markets which is likely to facilitate the transfer of permits and to enhance the liquidity of the system, but it also highlights that a remarkable bundle of transactions is among not regulated entities. This should be taken into account in the design of EU ETS policies. Their total number of transactions as transferring or acquiring accounts is almost comparable: 363,404 vs. 348,719 , similarly for the amounts of traded units $(27,585,732,942$ vs. $23,506,873,567)$.

Transfers involving only OHAs and PHAs account for 57.41 percent of the transactions and the 15.84 of the overall volume $(377,028$ transactions for $24,685,969,647$ traded units). It is worth recalling that the set of transactions here considered includes the entire compliance process which represents a significant share of the transfers. As already pointed out above, the core of the analysis will instead focus on pure transactions.

${ }^{8}$ EUTL transactions data set presents two levels of information for each counterpart, corresponding to the Transferring/Acquiring identifier in the registry and the Transferring/Acquiring account holder name to which the identifier is related. The account types refer here to the Transferring/Acquiring identifiers. Main accounts participants are reported in Appendix A.3. 
Finally, since OHAs and PHAs can belong to the same parent company, a deeper representation would require to analyze the ownership structure of the accounts. This will be discussed in Section 4 .

Furthermore, there are other types of accounts which relate to specific types of transactions. For instance, PAs indicate accounts related to the CDM registry ${ }^{9}$, which explains why we observe this type only as a transferring account. The lion's share of transactions involving HAs refer to (Party) Holding Accounts through which allowances are for instance allocated and surrendered and to a bundle of other government or EU Commission accounts used to manage administrative transfers. Finally, NAs are accounts for which information is not completely available; for these transfers not only the transferring/acquiring type is not directly available, but also the identity of the counterparts is often present only in the details of the transaction. As will be discussed in Section 3, the provision of additional scenarios with the inclusion of PAs, HAs and NAs aims to show how these specifications affect the structure of the EU ETS. Appendix A.2 will present a detailed focus on these account types.

\subsection{EU ETS Transactions Overview}

Figure 1 shows which are the key account types involved in the main transaction types. The core specification, which includes codes 3-0, 3-21 and 10-0, indicates that a large share of the total transferred amount occurred between similar counterparts.

Figure 1: Distribution of Transaction Types vs. Account Types. For each transaction type we show its distribution in terms of transferred units per account types: Operator Holding Accounts (OHAs), Person Holding Accounts (PHAs), Holding Account (HAs), and account with incomplete information (NAs). We consider the most frequent transaction types which represent the core of our study: 3-21 (external transfers 2005-2007), 3-0 (external transfers 2008-2012), 10-0 (internal transfers) and their aggregate overall sample. The first account code in the pair refers to the transferring account, while the second stands for the acquiring one. The Others slice is the complement to one of the main pairs of counterparts reported in the plot. Source: authors' own elaborations based on the EUTL transactions data set for the first two Phases.

External Tranfers (2005-2007)

(PHAs;PHAs) 64\%

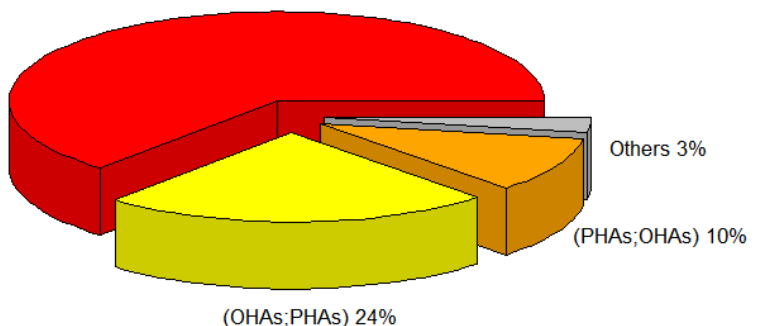

(OHAs;PHAs) 24\%
External Tranfers (2008-2012)

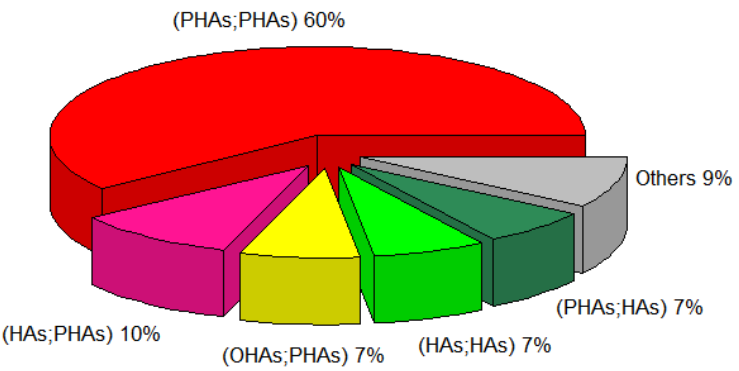

Internal + External Tranfers

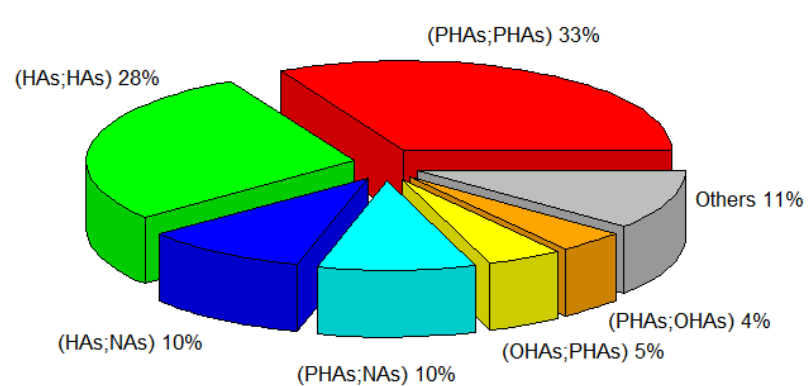

More precisely, 33 per cent occurred between PHAs, while 28 per cent involved HAs as both transferring and acquiring counterparts. Conversely, OHAs are not very likely to trade among each other (representing about 1.7 per cent of the traded amount), but are relevant counterparts for the other account types. Transactions involving OHAs and PHAs (within each group and between them) represent about 43 per cent of

${ }^{9}$ The link between EU ETS and the International Transaction Log (ITL) is established under the United Nations Framework Convention on Climate Change (UNFCC). 
the transferred amount, while the subset of OHAs and HAs accounts for about 32 per cent of the overall volume. The perimeter of transactions including only HAs, OHAs, and PHAs represents more than 78 per cent of the overall traded amount in the core specification. The marginal role of transfers between OHAs only is confirmed once we focus on internal transactions (about 2 per cent) and it becomes even more residual for external transactions (about 0.5 per cent). PHAs as both transferring and acquiring counterparts are much more active across registries, representing about 60 per cent of the overall volume compared to 23 per cent for internal transactions. The percentage of external traded amount reaches a value of 74 per cent once PHAs and OHAs are jointly considered (it is about 32 per cent for internal transfers). Thus, flows between national registries highlight that PHAs play the key role in this market, facilitating the transfer of permits among registries and outclassing the impact of OHAs. This is a sign of the importance of PHAs (which might be related to non-EU ETS regulated entities) for a proper establishment of a European market for allowances, which otherwise would probably be confined within national borders. HAs are very present within internal transfers, being involved in 36 per cent of the traded amount as both counterparts; this share increases to 41 per cent once the combined perimeter of OHAs and HAs is considered. By contrast, this percentages falls for the external case where they account for less than 7.5 per cent of the traded amount. If we look at the evolution of external transactions distinguishing between Phase I (code 3-21) and Phase II (code 3-0), it can be observed a remarkable decrease with respect to the overall volume in the share of transactions between only PHAs and OHAs, from around 99 per cent in Phase I to an overall 72 per cent in Phase II due to the impact of transactions involving HAs. Finally, it is important to stress that a large share of internal transactions involve NAs, while among external transactions their role tend to disappear. This seems to suggest that reports on transfers between actors operating in different registries are much more accurate and detailed than those within single registry where a relevant part of the transaction information is lost.

Figure 2: Transactions Distributions. Each plot shows the amount of transferred allowances (in millions) and the number of active registries (either transferring or acquiring registries) for different account types specifications: only OHAs, only PHAs, OHAs \& PHAs, and all the account types. Transactions are aggregated on a monthly basis. We consider transactions with type codes equal to: $3-0,3-21$, and 10-0. Source: authors' own elaborations based on the EUTL transactions data set for the first two Phases.
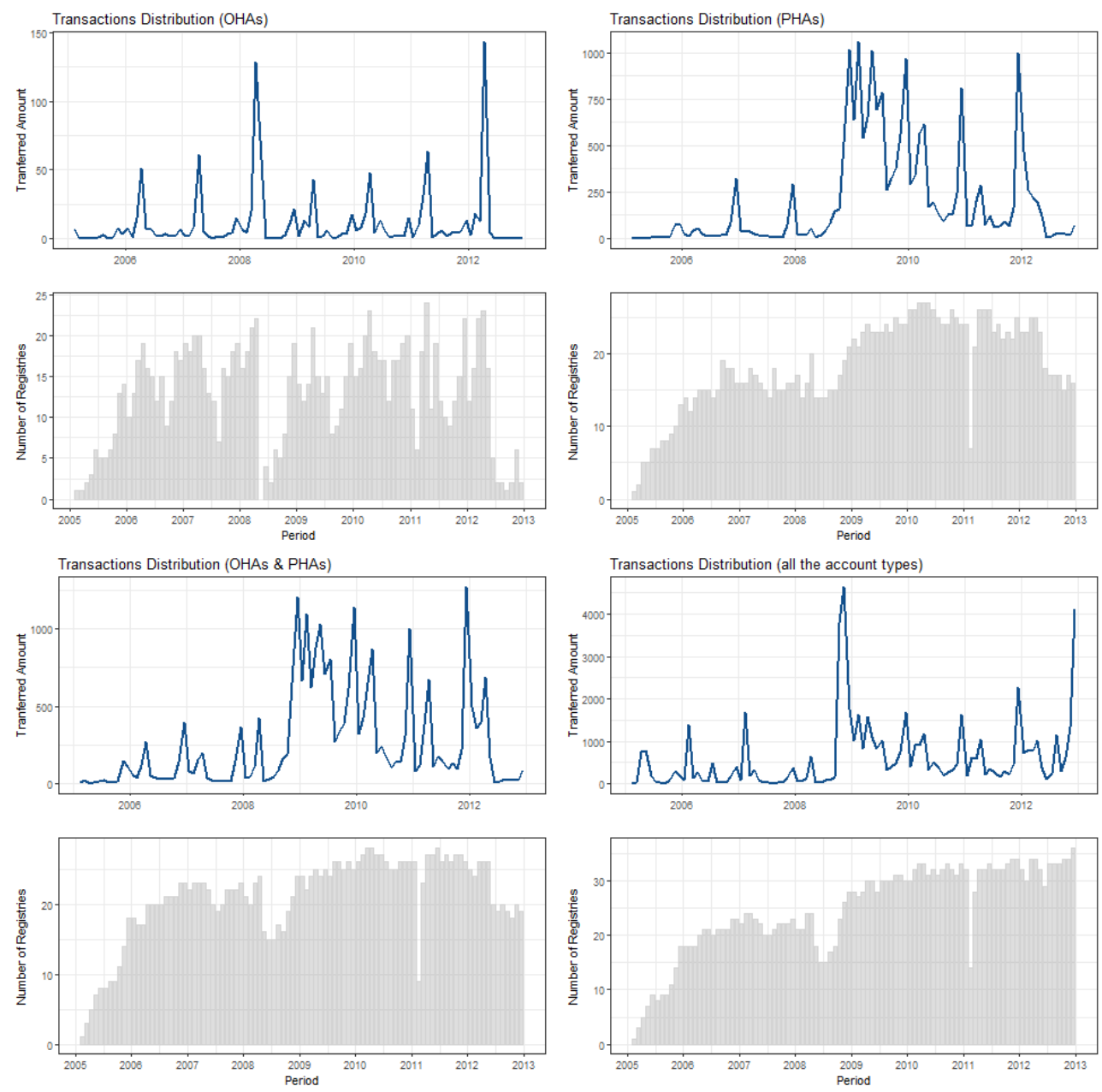

Figure 2 shows the distributions over time of both traded units and active registries according to different account types specifications ${ }^{10}$. It reveals that transactions among OHAs are much more likely to present

\footnotetext{
${ }^{10} \mathrm{~A}$ more specific representation of the flows of allowances in time which involve OHAs and PHAs is shown in Appendix A.4.
} 
regular seasonal spikes in correspondence of compliance periods. Interestingly, as expected PHAs became more active during Phase II, although the onset of financial crisis of mid-2007 might have played a role in the decreasing pattern which seems to emerge after 2009. The second half of 2012 shows an abrupt reduction in the activity of OHAs and PHAs in terms of both traded units and in the number of national registries. This is clearly influenced by the transition to the new Union Registry in the middle of 2012 that modified the classification of the accounts. ${ }^{11}$ The picture depicted by combining transactions between OHAs and PHAs is in line with that discussed for the PHAs case. In general, for transactions involving PHAs (either among themselves or with OHAs) Phase II coincides with an increase in both the traded volumes and the number of national registries involved. A different trend results once we enlarge the data set to include more types of accounts (i.e., OHAs, PHAs, HAs, PAs and NAs). In this case, the inclusion of (Party) HAs through which allowances are allocated and surrendered contributes to the observed regularities in the number of transferred allowances which emerge in the diagram. Finally, the spikes that can be observed at the end of solar years and around compliance dates are likely to reflect the delivery of forward and futures contracts.

\subsection{Registry vs. Country}

EUTL data allow us to distinguish between the registry of the account, which stands for the national administrator for that entity, and the country where this account is located. An account can be opened in a different registry with respect to the country of origin for several reasons. These may include favourable account set up requirements, fiscal advantages or the establishment of dedicated exchange platforms which require to open an account in the corresponding national registry.

A difference between the country of origin and the actual national administrator is itself a sign of attractiveness of certain Member States. It may influence the structure of the system and, in turn, the centrality of these states within the EU ETS ${ }^{12}$. Section 4 will discuss the result of the topological study, focusing on those registries which have been more central during the first two Phases. Here we anticipate summary descriptive statistics for those accounts for which national administrators differ from their countries of origin, leaving to Section 4 the discussion of the impact of these differences.

In the EUTL, there are more than $15 \mathrm{k}$ accounts which refer to about $10.5 \mathrm{k}$ account holders. Among them, more than $1.5 \mathrm{k}$ accounts present countries of origin that are different from their national administrators. Below, we summarize the most relevant discrepancies:

- Denmark: about 32 per cent of these differences refer to accounts selecting Denmark as their national registry; among their countries of origin the most frequent are United Kingdom, Germany, France and Spain; Denmark is also able to attract many accounts from financial markets outside Europe, like for instance Hong Kong, UAE, and Singapore;

- United Kingdom: it receives about 18 per cent of the accounts who register outside their countries of origin; the majority comes from USA and Switzerland, while a bundle of other accounts refers to Anglo-Saxon countries (e.g. from Australia, Bahamas, Bermuda, Canada, Cayman Islands, Gibraltar, and South Africa);

- France: about 14 per cent of the moving accounts are registered in France; they mainly refer to the United Kingdom, although also Switzerland and USA are well represented; this percentage was about 41 per cent for transfers in Phase I;

- Netherlands: about 10 per cent of the moving accounts are opened in the Netherlands; most of these come from the United Kingdom, and to a lesser extent from Switzerland, France, Belgium, and Germany;

- Germany: it is the national administrator for about 7 per cent of these moving accounts; their countries of origin are mainly Switzerland, the United Kingdom, and USA.

About half of the accounts which decided to register in a state different from their country of origin selected Denmark or the United Kingdom as their national administrators. During Phase I, France has been a very attractive center due to the presence of BlueNext as dedicated exchange platform for trading in permits; its suspension after the VAT fraud carousel contributes to explain its fall in terms of receiving accounts from different countries. This anticipates the results of Section 4, where we discuss the high centrality values of these Members States within the EU ETS and we present the decreasing pattern of France in terms of centrality.

Moreover, the total transferred amount which involves at least one of these accounts as either transferring or acquiring counterpart is less than 10 per cent once we consider the complete list of transactions types, but it becomes about 20 per cent once we focus on the core specification (transaction codes: 3-0, 3-21, and 10-0). Hence, the impact of these accounts on the structure of the EU ETS system seems not to be negligible. In particular, Phase II results much more affected by these migrations, whose traded volume almost doubled with respect to Phase I. As one might suspect, the lion's share of the transferred amount of units refers to external transactions.

\footnotetext{
${ }^{11}$ After the switch in mid-2012 from the national Kyoto registries to the EU section of the Union registry, the new OHAs and PHAs are included within HAs. See Appendix A.2 for further details.

${ }^{12}$ We thank an anonymous referee for pointing out this important aspect.
} 


\section{Methodology}

In recent years, complex systems' methodologies have been applied in several fields in order to analyze the features of a system ${ }^{13}$. This literature spreads from the representation of social relationships (e.g. friendships or co-authorship) and economic phenomena (e.g. system risk assessment within financial networks or corporate ownership networks) to infrastructure applications (e.g. power grids or the world wide web). The basic ideas behind these studies rely on the description of a system as a graph or a network $G=(V, E)$, where $V$ is the set of nodes representing the agents and $E$ is the set of edges which stand for the links (e.g. economic or physical, either directed or not) between pairs of nodes. In particular, in a directed network if $i$ and $j$ are two nodes and there is an edge from $i$ (i.e., source) to $j$ (i.e., target), then this is represented as the pair $(i, j) \in E$, and we say that $i$ is a neighbour of $j$. Hence, the network is characterized by an adjacency matrix $A$, where $A_{i j}=0$ if there is no edge from $i$ to $j$, while is $A_{i j}=1$ if such edge exists. Alternatively, a weighted version $(W)$ of the adjacency matrix assigns a weight to each edge.

Formally, in our framework each node $i$ refers to a registry (represented by the registry code ${ }^{14}$ ), while the directed edge $(i, j)$ is weighted according to the amount of transferred allowances from the transferring registry $i$ to the acquiring registry $j$. The choice to rely on a registry-level representation is in line with the structure of EU ETS that was originally established from national registries. We believe that recognizing the presence of very central registries or, alternatively, of a more uniform system would be important for the EU ETS design. On the one hand, a more homogeneous distribution of transactions in the network can signal a more mature market with higher participation across countries. On the other hand, a high concentration of the exchanges in a few more central registries can enhance liquidity and may facilitate the regulation of the overall system. This exploratory analysis aims to provide a first insight into the inter-temporal evolution of the EU ETS network structure, providing a topological analysis of the system along the first two Phases ${ }^{15}$. In order to study how the overall structure of the network has evolved over time, we build a stream of networks one for each month from April 2005 to December $2012^{16}$, thus aggregating transactions on a monthly basis. Since our aim is to investigate the evolution over time of the EU ETS, we prefer to use a monthly frequency to build the networks. This choice ensures a good availability of transactions for each period and registry, allowing us to describe how the system has changed during the first two Phases. Subsection 3.1 will present the network measures used to characterize both the configuration of the system and the role played by each registry/node.

We map topological changes in the structure of the EU ETS, so as to reveal the possible presence of very central national registries/nodes. As pointed out above (Section 1), if this is the case, PHAs are likely to play a relevant role, as they can register outside the country of origin. In order to disentangle the role of the different types of account (e.g. OHAs, PHAs and HAs), we provide a description of the EU ETS by focusing on different levels of aggregation of both accounts and transactions types. This allows to describe how the inclusion of PHAs or HAs (and their related types of transactions) in the OHAs framework may have influenced the structure of system.

These specifications are computed according to a reference scenario where only internal and external transactions are considered (aggregating codes 10 and 3, see Table 1). A proxy for pure transfers that excludes the main administrative transactions is represented by those with codes 3-0, 3-21, and 10-0, which accounts for 74 per cent of the overall transactions and 54 per cent of total volumes being transferred in the reference scenario. This framework allows us to focus on the impacts of pure transfers, either within the same national registry or across registries ${ }^{17}$. In particular, we consider the following specifications which basically show the EU ETS from different facets:

- case I: transactions between OHAs only. This case considers operators subject to the EU ETS, which

\footnotetext{
${ }^{13}$ For a deep analysis of Network Theory methodologies and applications, the interested reader can refer to e.g. Newman (2003) and Jackson (2010), among others.

${ }^{14}$ We use the same notation reported in the EUTL. Specifically, AT: Austria, AU: Australia, BE: Belgium, BG: Bulgaria, CDM: Clean Development Mechanism, CH: Switzerland, CY (CY0): Cyprus, CZ: Czech Republic, DE: Germany, DK: Denmark, EC: European Commission, EE: Estonia, ES: Spain, FI: Finland, FR: France, GB: United Kingdom, GR: Greece, HU: Hungary, IE: Ireland, IS: Iceland, IT: Italy, JP: Japan, LI: Liechtenstein, LT: Lithuania, LU: Luxembourg, LV: Latvia, MT (MT0): Malta, NL: Netherlands, NO: Norway, NZ: New Zealand, PL: Poland, PT: Portugal, RO: Romania, RU: Russian Federation, SE: Sweden, SI: Slovenia, SK: Slovakia, UA: Ukraine.

${ }^{15}$ We could have provided a more granular representation of the system (e.g. at firm-level), however we preferred not to build here larger networks with many nodes poorly connected. In fact, most of the accounts are scarcely present during a trading period, being active only in few intervals. This implies that a firm-level network representation would be based on aggregated flows on large time windows, probably at the cost of a poorly informative network temporal analysis. The exploitation of firm-level information to build networks is left for future research.

${ }^{16}$ We discard February and March 2005 because there were only few transactions. In addition, we join together registry codes CY with CY0 and MT with MT0. For the sake of simplicity, we merge non-EU countries with CDM: we named Others the resulting node.

${ }^{17}$ As robustness check we also include the other types of transactions more frequent in the EU ETS, namely: Allowance Surrender (code 10-2), Allowance Issue for 2008-2012 Onwards (code 10-52), Allowance Allocation (code 10-53) and Surrendered Allowance Conversion (code 10-61). This enlarged scenario is almost totally representative of the perimeter of internal and external transactions in terms of both the number of transfers and the amount of transferred units. These results (provided in the Appendix) are basically coherent with the reference specification. A further partition of the EU ETS might involve also the unit type (e.g. general allowances, CERs, ERUs, RMUs, etc.), but this goes beyond the scope of our paper. A brief overview of the number of units for different unit types is available at: http://ec.europa.eu/environment/ets/registryHoldings.do? search=Search.
} 
use the account mainly for compliance purposes. As shown in Section 2, transactions circumscribed within the OHAs perimeter are marginal compared to the overall volume;

- case II: transactions between PHAs only. These are voluntary trading accounts in the EU ETS registry. As shown in Table 2 and Figure 1 they represent key counterparts in the trading of allowances, being very active across registries and for many types of transactions. Their role is likely to dominate the structure of EU ETS given the amount of transferred allowances and the number of transactions in which they are involved;

- case III: OHAs \& PHAs. This configuration represents the baseline for the trading of allowances in the EU ETS, since it focuses on the two most important account types, which are in part related to each other due to the common ownership structure for some accounts;

- case IV: OHAs \& PHAs \& HAs. It enlarges case III by adding other types of account, mainly government accounts, through which allowances are issued, allocated and surrendered. When considering transactions types 3-0, 3-21, and 10-0 (the focus of our analysis), (Party) Holding Accounts represent about 80 per cent of the total amount of units transferred by $\mathrm{HAs}^{18}$.

- case V: OHAs \& PHAs \& HAs \& PAs \& NAs (hereinafter, the "All" case). This case can be seen as an extension of case IV. It includes transactions referring to the CDM registry (whose impact is limited) as well as those involving at least one counterpart for which account information is only partially available.

\subsection{Network Measures}

Our investigation strategy introduces a novel approach based on basic network theory tools. We decide to depict the topological structure of the EU ETS by proposing intuitive indicators for both local and global properties of the network. In particular, we describe how the overall system has evolved during the sample period, focusing on the likelihood of each node to form connections with the others.

Given a certain network, one may want to disentangle the importance of the nodes by providing a ranking according to measures of centrality. The concept of centrality might be translated into more qualitative meanings such as popularity (e.g. in social networks) or systemic importance (in systemic risk assessment). In our case, more central nodes represent those national registries which play a more active role in the EU ETS. For instance, some countries may trade more allowances than those required to fulfill the Kyoto Protocol obligations, or may play the role of hubs in the system which connect two or more geographical areas. The use of centrality measures, moreover, allows to evaluate the impact on the network's structure of the enlargement of the EU ETS perimeter to other Member States and to show how globally the structure of the EU ETS has changed over time. In this regard, it is particularly relevant to distinguish between the presence of a network where connections are almost evenly spread among pairs of nodes and the emergence of a polarized network with some core and well connected nodes which are surrounded by a cloud of peripheral nodes.

Below we provide a description of the network measures utilized to describe the EU ETS. In particular, given a graph $G$ with $N$ nodes and a weighted adjacency matrix $W$ (in which the weight, $w_{i j}$, is the amount of allowances transferred from $i$ to $j$ ), we decided to focus mainly on the following three network measures ${ }^{19}$ :

- In/Out-Strength. This measures computes the weighted degree of a node. Since the network is directed, we can consider either the amount of weighted edges attaching the node (In-Strength) or those departing from that node (Out-Strength). These measures are computed as $s_{i}^{I n}=\sum_{j=1}^{N} w_{j i}$ and $s_{i}^{\text {Out }}=\sum_{j=1}^{N} w_{i j}$, respectively. The average In(Out)-Strength of a graph is, therefore, the average of its nodes' In(Out)-Strengths ${ }^{20}$.

- PageRank. This measure computes a ranking of nodes according to the structure of the incoming edges. It represents a variation of the eigenvector measure of centrality which has shown to be a very suitable approach to address the issue of the singularity of the adjacency matrix due to the presence of dangling nodes (namely, nodes without outgoing edges). In the context of the World Wide Web (where the algorithm was originally developed), the intuition behind this measure is that a page has a high rank not only if its incoming links are many, but also if it has a few highly ranked

\footnotetext{
${ }^{18}$ After the deployment of the EU section in the Union registry, in mid-2012 the set of HAs was enlarged to include other types of accounts (see Appendix A.2 for further details). Since our analysis finishes with Phase II at the end of 2012, this change, however, had little impact on the composition of the HAs in our sample.

${ }^{19}$ Several other network measures have been used in the analysis, e.g.: Average Neighborhood In/Out Strength, In/Out-Degree, Degree Centrality, Closeness Centrality and Betweenness Centrality, among others. They are omitted here for space and clarity reasons, but results are available from the authors upon request.

${ }^{20}$ In addition, the un-weighted versions (i.e. the In/Out Degree) can be computed using the (un-weighted) adjacency matrix $A$ as follows: $k_{i}^{I n}=\sum_{j=1}^{N} a_{j i}$ and $k_{i}^{\text {Out }}=\sum_{j=1}^{N} a_{i j}$, where $k_{i}^{\text {In }}\left(k_{i}^{\text {Out }}\right)$ denotes the $\operatorname{In}($ Out $)$-Degree of node $i$. Finally, with $s_{i}$ and $k_{i}$ we refer to node $i$ un-directed versions (i.e. simply the Strength and the Degree of node $i$ ).
} 
incoming links. Therefore, to determine the centrality of node $i$ it exploits not only the amount of its incoming links (as approximated for instance by the In-Strength of node $i$ ), but it also considers how its neighbourhoods are connected to $i$. This feature makes the PageRank an appealing indicator and motivates the exploitation of its variants even in several economic and social fields, such as: financial networks and the assessment of systemic risk (Battiston et al., 2012; Hautsch et al., 2014), social networks (Kwak et al., 2010), multiplex networks (Halu et al., 2013), trade networks (Ermann and Shepelyansky, 2011), urban transportation networks (Agryzkov et al., 2012), the ECommerce (Oestreicher-Singer and Sundararajan, 2012), among others. The value of the PageRank can be defined recursively according to the formula ${ }^{21}: P R(i)=\frac{1-d}{N}+d \sum_{j \rightarrow i} \frac{P R(j)}{L(j)}$, where $P R(i)$ is the PageRank of node $i, N$ is the number of nodes, $L(j)$ is the total amount of links originating from $j$ and the sum is taken over all nodes $j$ having a link to node $i$. The quantity $d$ ranges between 0 and 1 and represents the impact of a dumping factor, namely, the probability that a given link can arise anywhere. Hence, the quantity $\frac{1-d}{N}$ guarantees that the adjacency matrix will be non-singular. As in the default case, here $d$ is set equal to 0.85 .

- Assortativity. This measure is based on the Pearson correlation between the strength of each pair of connected nodes. It basically measures the propensity of the nodes to connect to similar counterparts, that is, to other nodes in the network having similar strenght. Hence the coefficient ranges between +1 and -1 . The network is said to have perfect assortative mixing patterns when the coefficient assumes a value equal to +1 , it is non-assortative when the coefficient is 0 and it is completely disassortative when the value is -1 . To provide an intuitive interpretation of the Assortativity measure, if the network has high assortativity, nodes that are more active in terms of number of transactions and transferred amount are more likely to connect to others that are also very active in the network. For directed graphs (as in the present case), assortativity coefficients are computed according to both source and target nodes. This means that coefficients are computed between pairs of connected nodes according to different specifications of their respective distributions of inflows or outflows and their combinations (see e.g. Newman, 2002). Denoting with Out the source node and In the target one, this means that we can have four possible combinations: In-In, Out-Out, In-Out and Out-In. In formula, given $\alpha$ and $\beta$ the directions of the flows for the nodes of the edge $i$, the assortativity coefficient is: $r(\alpha, \beta)=\frac{\sum_{i}\left(j_{i}^{\alpha}-\bar{j}^{\alpha}\right)\left(k_{i}^{\beta}-\bar{k}^{\beta}\right)}{\sqrt{\sum_{i}\left(j_{i}^{\alpha}-\bar{j}^{\alpha}\right)^{2}} \sqrt{\sum_{i}\left(k_{i}^{\beta}-\bar{k}^{\beta}\right)^{2}}}$, with $j$ and $k$ the corresponding strengths of the pair of connected nodes, whose respective average values are indicated with bars. $(\alpha, \beta)$ can be any combination of inflows and outflows. For instance, In-Assortativity is $r(i n, i n)$ and Out-Assortativity is $r$ (out, out), thus measuring how nodes connect with other nodes that have similar In- and Out- Strengths as themselves, respectively.

The EU ETS is therefore represented as a directed and weighted network since each node can have both attaching and departing links corresponding to the amount of acquired and transferred permits, respectively. In what follows we will use the three network measures described above as they offer insights on different aspects of the network. Basically, the In- or Out-Strength of a node measures the amount of In- or Outflows that point to that node or depart from it. This information is useful to describe how active the registries are in the market, highlighting those nodes that are more involved in the acquiring or transferring setups $^{22}$, respectively. While In- and Out- Strength provides a preliminary view on nodes' centrality rankings, eigenvector measures of centrality can offer a more thorough description of this aspect as they are more suitable to include the overall structure of the network. In fact, the configuration of the neighborhood matters in the assessment of centrality ${ }^{23}$. For this reason, we believe it is interesting to introduce a measure of eigenvector centrality that ranks registries taking into account not only their incoming links but also where these flows come from, thus including the structure of the system in the measurement of the centrality scores. For this purpose, we exploit the PageRank to evaluate which nodes have been more central. Finally, to describe the general tendency of these nodes to form links, we apply the Assortativity coefficient, which can provide a characterization of how they are connected. We decide to exploit this indicator due to its similarity to the Pearson Correlation coefficient, thus opting for a simple and intuitive topological measure that is sufficient, however, to present the relationships between the centrality of the nodes and the propensity to form connections ${ }^{24}$.

\footnotetext{
${ }^{21}$ For a deep analysis on the computation of the PageRank, see e.g. Berkhin (2005) and Bianchini et al. (2005).

${ }^{22} \mathrm{~A}$ high level of In-Strength means that the corresponding node receives a large number of inflows, i.e. it acquires many permits; conversely, a high level of Out-Strength refers to a node that transfers many permits.

${ }^{23}$ For instance, if node $i$ receives part of its inflows from a very active node $j$, and $i$ is the only node to be connected to $j$, then node $i$ in some sense inherits the centrality of node $j$, while if node $j$ is connected to a wider list of nodes, then node $i$ will "receive" only a part of the centrality of node $j$.

${ }^{24}$ Consider for instance two nodes in 2007, one very central (DE) and the other in the periphery (CZ), and their respective outflows (transaction codes 3-0, 3-21, and 10-0). Given two other counterparts, again one very central (GB) and the other peripheral (SK), we observe that the portion of the outflows to GB is higher for DE (2.49 per cent) than CZ (1.27 per cent), while outflows to SK show the opposite pattern, that is 0.0036 per cent for DE and 0.2706 per cent for CZ. Similar results apply to other central (peripheral) nodes, suggesting that in 2007 more central (peripheral) nodes tend to trade among each other (for centrality rankings see Table 3).
} 


\section{Results and Discussion}

We describe the EU ETS according to two different perspectives. Firstly, we investigate which registries have played a central role in the transferring of allowances. Secondly, we analyze the evolution of the structure of the system and the way registries are connected to each other. In particular, for the first goal we analyze the PageRank, while for the second we exploit the Assortativity coefficient. Results are shown for different types of account (e.g. only OHAs or PHAs separately or a wider set of types of account) and for two distinct periods corresponding to the first two phases of the EU ETS program (Phase I: 2005-2007 and Phase II: 2008-2012). This allows us to depict the system with respect to the characteristics of the accounts involved in the transactions and according to two different regulatory frameworks.

Figure 3: EU ETS network: case II (only transactions between PHAs). Data refer to transferred allowances from Apr-2005 to Dec-2012 with transaction type codes equal to 3-0, 3-21, and 10-0. The size of the node is proportional to the In-Strength, while the colour is based on the PageRank of the node and it ranges from blue (lower values) to red (higher values). Networks are drawn not oriented for representativity purposes. Source: authors' own elaborations based on the EUTL transactions data set for the first two Phases.

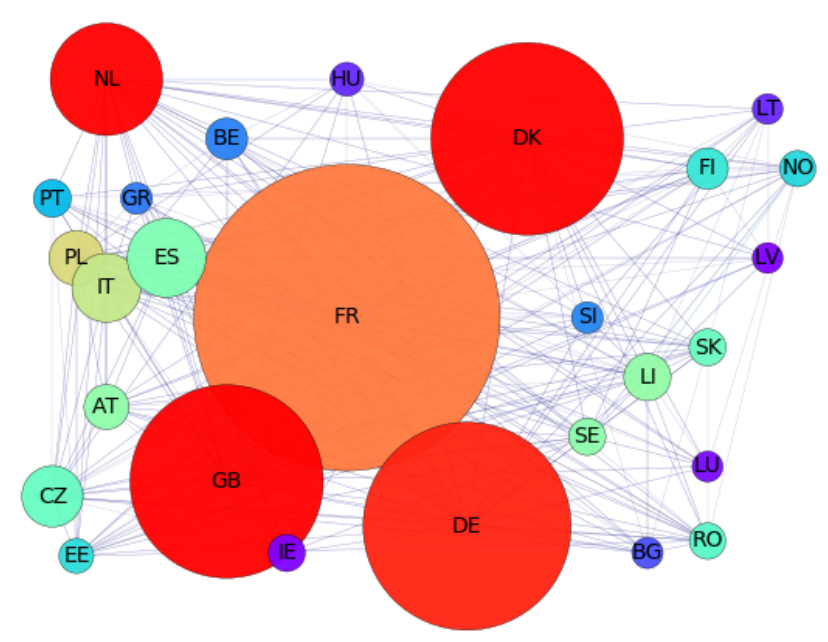

Figure 4: EU ETS network: case III (transactions involving OHAs and PHAs). Data refer to transferred allowances from Apr-2005 to Dec-2012 with transaction type codes equal to 3-0, 3-21, and 10-0. The size of the node is proportional to the In-Strength, while the colour is based on the PageRank of the node and it ranges from blue (lower values) to red (higher values). Networks are drawn not oriented for representativity purposes. Source: authors' own elaborations based on the EUTL transactions data set for the first two Phases.

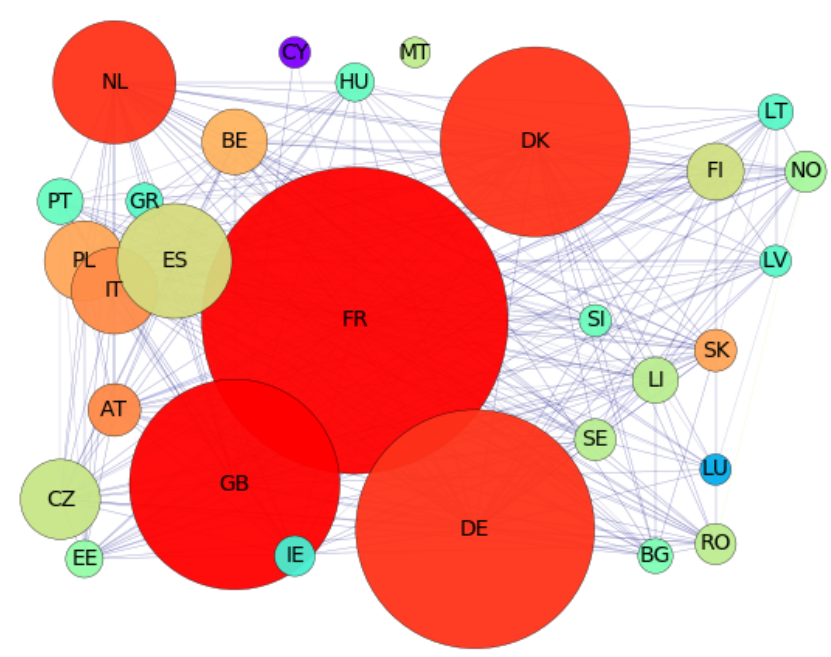

Figures 3 and 4 show the EU ETS networks that emerge from case II (that considers only transactions between PHAs) and case III (that takes both OHAs and PHAs jointly into account). The sizes of the nodes in the figures are proportional to their In-Strengths, while the colour indicates their PageRanks on 
an increasing scale ranging from blue to $\mathrm{red}^{25}$. As is shown in the plots, the biggest nodes generally tend to be red, namely, registries that have the highest In-Strengths (i.e. the largest amount of incoming flows) often have also the highest PageRanks (i.e. they are more central in the network). However, the measures of In-Strength and PageRank do not always go hand in hand as one could expect (see subsection 3.1). For instance, this is confirmed in Figure 4 by registries AT, BE, IT and PL that are brown although their size is rather small. In other words, their centrality scores measured by their PageRanks is much higher than their In-Strengths values. The same consideration emerges from a cross-registry comparison. Consider, for instance, ES and NL in Figure 4: although the two registries have similar In-Strengths (same size of the nodes), NL turns out to be much more central than ES in the EU ETS network (colours being red versus light green). The greater centrality of the NL in the network compared to ES might partially reflect the difference in the national rules, which attracted many foreign companies to open accounts in the NL registry (see subsection 2.4 above and Table 4 below) thus determining more active exchange levels in NL than in ES. Similar considerations might explain why DK emerges as one of the most central nodes in the network. In the early phases of the EU ETS, in fact, the DK registry had very weak legal requirements to open a new account. The rules for opening accounts were adopted in DK only at the end of Phase II, which may explain why DK maintained a remarkable centrality in both phases ${ }^{26}$. Finally, notice that for a given registry its size and colour may change as we move from Figure 3 to Figure 4. This suggests that the inclusion of different types of account influences the overall configuration, so that some registries turn out to be more central in the OHAs \& PHAs case than in the OHAs specification, and vice versa. This motivates the study of different facets of the EU ETS.

In Table 3 we summarize the results of the centrality measures. In the analysis that follows, we will focus on the PageRank due to both its novelty in this field and its ability to catch non-linear effects. PageRank values range from 0 (no central node) to 1 (very central node). In order to replicate the same range, in Table 3 we report the average of monthly values for each Phase and specification ${ }^{27}$ and their corresponding standard deviations. A few interesting results emerge from the analysis.

In the first place, although results for OHAs and PHAs separately are often quite comparable for the same node, there are some cases where a registry is more central for a certain type of account and less for the other. For instance, DE is almost two times more central than the second most central node in the OHAs framework over the entire reference period, while in the PHAs case DE is fairly comparable with other registries (DK, FR, GB and NL). Conversely, the latter set of registries (i.e., DK, FR, GB and NL) shows an opposite pattern, being more central within the PHAs perimeter than in the OHAs case.

In the second place, it seems that the role of PHAs dominates the other types of account. This might be due to the number and value of transactions which involve PHAs with respect to the other types of account as emerges from Table 2. The importance of the PHAs can be easily seen by comparing the results reported in Table 3 in the PHA column with those reported in the columns that follow. Indeed, the values for OHAs \& PHAs turn out to be very near to the ones in the PHAs case. Moreover, even the inclusion of the other types of account reported in the following columns (columns OHAs \& PHAs \& HA and ALL) has only a marginal impact with results that remain comparable with those of the OHAs \& PHAs specification. Its is important to stress that this finding holds not only under the core scenario (transaction codes 3-0, 3-21, and 10-0), but also under the alternative scenario (see Appendix 8) which involves a more comprehensive set of transactions (e.g. allowance surrender, issue and allocation) and a more active role of the other types of accounts (e.g., HAs).

In the third place, as regards the comparison between the two Phases we observe that those registries that were less central in Phase I are more likely to remain far from the core of the network also in Phase II in almost every type of account specification. For instance, this is the case of smaller markets (e.g. CY, EE, GR, IE, LT, LU, LV, and MT) which usually are not influenced by significant flows of transactions. Other countries, instead, experienced a change in their centrality over time. For instance, we observe that some registries such as AT, CZ, ES, and FR in the OHAs case, and BE, PL, PT and SK in both OHAs and PHAs cases became more central once entered in Phase II, while opposite behaviours between the two Phases under OHAs or PHAs specifications are observed for AT, FR and IT.

Finally, we notice that for each type of account specification the highest values of PageRank in Phase II are usually below those observed during Phase I, thus suggesting the emergence of a more homogeneous system with less clear very central nodes. Centrality scores show, in fact, slightly decreasing pattern from Phase I to Phase II, thus suggesting that transactions are more spread throughout registries after the learning Phase. This might be due to the fact that at the beginning of the EU ETS program some countries were more able to implement trading platforms which facilitated their central position in the transferring of allowances across registries and operators, while once other Member States joined the program the structure of the system became less polarized. This might have weakened the role of some registries as hubs for the transfer of allowances, although a ranking in the centrality is still present along Phase II. In addition, the emergence of a more homogeneous system might be partially ascribed also to the entrance into the EU ETS program of new registries during Phase II (e.g. BG, IS, LI, NO, RO, and outside Europe registries).

${ }^{25}$ The whole rainbow of colours represented in the figures ranges from lower to higher PageRanks as follows: blue, purple, light blue, light green, green, brown, red.

${ }^{26}$ See Appendix A.11 for a representation of the network in each Phase.

${ }^{27}$ In Table 3 for each registry we report in bold the weighted average for the entire reference period (or only the value of Phase II if that registry is not present in Phase I), where weights are assigned according to the number of months in each Phase. 
Table 3: Network Statistics: PageRanks. For each registry we show different specifications according to specific subsets of account types: OHA, PHA, OHA \& PHA, OHA \& PHA \& HA, and all types of accounts, respectively. We report the mean values (mean) of the period and the standard deviation (sd). Values are shown separately for Phase I and Phase II of the EU ETS program and for the overall sample period (in bold). Source: authors' own elaborations based on the EUTL transactions data set for the first two Phases.

\begin{tabular}{|c|c|c|c|}
\hline & & & \\
\hline & mean & sd & mean \\
\hline Austria (AT) & 0,04 & $5,61 \%$ & 0,04 \\
\hline Phase I & 0,01 & $1,28 \%$ & 0,06 \\
\hline Phase II & 0,06 & $8,00 \%$ & 0,04 \\
\hline Belgium (BE) & 0,04 & $5,68 \%$ & 0,02 \\
\hline Phase I & 0,04 & $6,61 \%$ & 0,01 \\
\hline Phase II & 0,05 & $5,17 \%$ & 0,03 \\
\hline Bulgaria $(B G)$ & 0,00 & $0,39 \%$ & 0,01 \\
\hline Phase II & 0,00 & $0,39 \%$ & 0,01 \\
\hline Cyprus (CY) & 0,00 & $0,78 \%$ & 0,00 \\
\hline Phase I & 0,00 & $0,00 \%$ & 0,00 \\
\hline Phase II & 0,00 & $1,21 \%$ & 0,00 \\
\hline Czech Republic (CZ) & 0,06 & $9,42 \%$ & 0,05 \\
\hline Phase I & 0,03 & $5,03 \%$ & 0,05 \\
\hline Phase II & 0,08 & $11,84 \%$ & 0,05 \\
\hline Denmark (DK) & 0,06 & $7,30 \%$ & 0,10 \\
\hline Phase I & 0,06 & $7,46 \%$ & 0,15 \\
\hline Phase II & 0,06 & $7,22 \%$ & 0,07 \\
\hline Estonia $(E E)$ & 0,01 & $2,40 \%$ & 0,01 \\
\hline Phase I & 0,02 & $2,85 \%$ & 0,00 \\
\hline Phase II & 0,01 & $2,16 \%$ & 0,01 \\
\hline European Commission (EC) & 0,00 & $0,00 \%$ & 0,00 \\
\hline Phase II & 0,00 & $0,00 \%$ & 0,00 \\
\hline Finland $(F I)$ & 0,07 & $8,91 \%$ & 0,04 \\
\hline Phase I & 0,07 & $9,94 \%$ & 0,05 \\
\hline Phase II & 0,06 & $8,35 \%$ & 0,04 \\
\hline France (FR) & 0,07 & $10,81 \%$ & 0,10 \\
\hline Phase I & 0,04 & $4,48 \%$ & 0,11 \\
\hline Phase II & 0,09 & $14,28 \%$ & 0,09 \\
\hline Germany (DE) & 0,13 & $13,07 \%$ & 0,10 \\
\hline Phase I & 0,22 & $19,68 \%$ & 0,12 \\
\hline Phase II & 0,09 & $9,44 \%$ & 0,08 \\
\hline Greece (GR) & 0,01 & $2,45 \%$ & 0,01 \\
\hline Phase I & 0,00 & $0,42 \%$ & 0,00 \\
\hline Phase II & 0,02 & $3,57 \%$ & 0,01 \\
\hline Hungary $(H U)$ & 0,05 & $6,45 \%$ & 0,01 \\
\hline Phase I & 0,06 & $6,36 \%$ & 0,00 \\
\hline Phase II & 0,04 & $6,50 \%$ & 0,01 \\
\hline Iceland (IS) & 0,00 & $0,00 \%$ & 0,00 \\
\hline Phase II & 0,00 & $0,00 \%$ & 0,00 \\
\hline Ireland (IE) & 0,01 & $1,90 \%$ & 0,02 \\
\hline Phase I & 0,01 & $2,31 \%$ & 0,01 \\
\hline Phase II & 0,01 & $1,68 \%$ & 0,02 \\
\hline Italy $(I T)$ & 0,06 & $10,04 \%$ & 0,04 \\
\hline Phase I & 0,07 & $8,43 \%$ & 0,03 \\
\hline Phase II & 0,05 & $10,92 \%$ & 0,05 \\
\hline Latvia $(L V)$ & 0,01 & $2,59 \%$ & 0,00 \\
\hline Phase I & 0,02 & $3,21 \%$ & 0,00 \\
\hline Phase II & 0,01 & $2,25 \%$ & 0,00 \\
\hline Liechtenstein $(L I)$ & 0,00 & $0,00 \%$ & 0,01 \\
\hline Phase II & 0,00 & $0,00 \%$ & 0,01 \\
\hline Lithuania $(L T)$ & 0,01 & $2,43 \%$ & 0,01 \\
\hline Phase I & 0,01 & $2,47 \%$ & 0,01 \\
\hline Phase II & 0,01 & $2,41 \%$ & 0,01 \\
\hline Luxembourg $(L U)$ & 0,00 & $0,65 \%$ & 0,01 \\
\hline Phase I & 0,00 & $0,27 \%$ & 0,00 \\
\hline Phase II & 0,00 & $0,86 \%$ & 0,01 \\
\hline Malta $(M T)$ & 0,00 & $2,26 \%$ & 0,00 \\
\hline Phase I & 0,00 & $1,17 \%$ & 0,00 \\
\hline Phase II & 0,00 & $2,86 \%$ & 0,00 \\
\hline Netherlands (NL) & 0,04 & $6,01 \%$ & 0,09 \\
\hline Phase I & 0,06 & $6,32 \%$ & 0,11 \\
\hline Phase II & 0,03 & $5,83 \%$ & 0,08 \\
\hline Norway (NO) & 0,01 & $1,68 \%$ & 0,01 \\
\hline Phase II & 0,01 & $1,68 \%$ & 0,01 \\
\hline Others & 0,00 & $0,00 \%$ & 0,00 \\
\hline Phase II & 0,00 & $0,00 \%$ & 0,00 \\
\hline Poland (PL) & 0,04 & $4,70 \%$ & 0,04 \\
\hline Phase I & 0,02 & $3,16 \%$ & 0,02 \\
\hline Phase II & 0,05 & $5,55 \%$ & 0,05 \\
\hline Portugal (PT) & 0,04 & $6,16 \%$ & 0,02 \\
\hline Phase I & 0,03 & $3,36 \%$ & 0,01 \\
\hline Phase II & 0,05 & $7,69 \%$ & 0,03 \\
\hline Romania (RO) & 0,00 & $1,32 \%$ & 0,01 \\
\hline Phase II & 0,00 & $1,32 \%$ & 0,01 \\
\hline Slovakia (SK) & 0,02 & $3,34 \%$ & 0,02 \\
\hline Phase I & 0,01 & $1.70 \%$ & 0,01 \\
\hline Phase II & 0,03 & $4,25 \%$ & 0,03 \\
\hline Slovenia (SI) & 0,01 & $2,15 \%$ & 0,01 \\
\hline Phase I & 0,01 & $2,93 \%$ & 0,01 \\
\hline Phase II & 0,01 & $1,72 \%$ & 0,01 \\
\hline $\operatorname{Spain}(E S)$ & 0,07 & $8,24 \%$ & 0,07 \\
\hline Phase I & 0,04 & $6,64 \%$ & 0,07 \\
\hline Phase II & 0,09 & $9,13 \%$ & 0,07 \\
\hline Sweden $(\boldsymbol{S E})$ & 0,03 & $3,92 \%$ & 0,04 \\
\hline Phase I & 0,07 & $7,44 \%$ & 0,04 \\
\hline Phase II & 0,01 & $1,99 \%$ & 0,04 \\
\hline Switzerland $(\mathrm{CH})$ & 0,00 & $0,00 \%$ & 0,00 \\
\hline Phase II & 0,00 & $0,00 \%$ & 0,00 \\
\hline Ukraine (UA) & 0,00 & $0,00 \%$ & 0,00 \\
\hline Phase II & 0,00 & $0,00 \%$ & 0,00 \\
\hline United Kingdom (GB) & 0,07 & $8,34 \%$ & 0,12 \\
\hline Phase I & 0,10 & $9,77 \%$ & 0,12 \\
\hline Phase II & 0,05 & $7,55 \%$ & 0,11 \\
\hline
\end{tabular}


To provide a more intuitive visual representation of the inter-temporal evolution of the market, we summarize below the behaviour of PageRanks over time ${ }^{28}$. As pointed out in Table 3, descriptive statistics on centrality measures suggest that many registries have played only a marginal role. Therefore, for reasons of clarity, to provide a simple visualization of the centrality of the registries over time we plot only a set of selected nodes. We focus on those registries that have been more active during the sample period: Denmark (DK), France (FR), Germany (DE), Great Britain (GB) and the Netherlands (NL), distinguishing different account type specifications as defined above.

Figure 5: PageRanks for different Account Types. Plot shows PageRank values for a selected list of central registries: Denmark (DK), France (FR), Germany (DE), Great Britain (GB) and the Netherlands (NL). We present four cases: OHAs, PHAs, OHAs \& PHAs, and all the account types specification. We refer to transaction types: 3-0,3-21, and 10-0. Source: authors' own elaborations based on the EUTL transactions data set for the first two Phases.
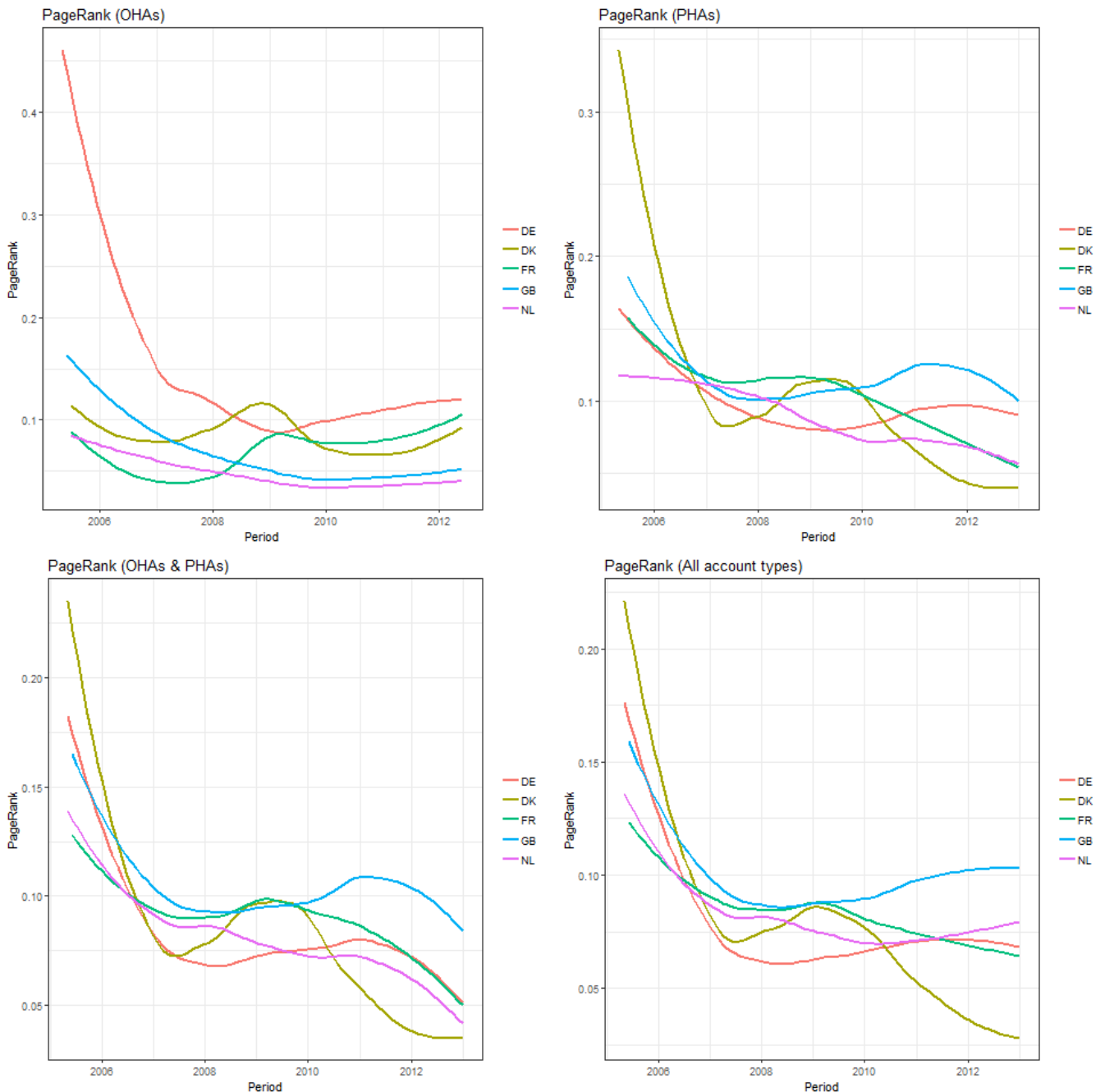

Figure 5 highlights that within OHAs (figure on the top-left in the panel) DE has played a central role during the reference period especially in the early stage of the EU ETS program. Interestingly, we can observe a general decreasing trend until mid-2008, while in the remaining of Phase II patterns are generally flattening out ${ }^{29}$. DK and FR seem to show bell-shaped behaviours around year 2009, with higher centrality scores in Phase II than in Phase I in the case of FR. Overall, the picture suggests the presence of a much clearer ranking in the centrality measure for Phase I, while in Phase II PageRanks are concentrated in a stricter range with unstable positions in the rankings. The switch from Phase I to Phase II coincides also with the outbreak of financial markets. One might be interested in the analysis of how the onset of the financial crisis affected the structure of the EU ETS and influenced the role of each registry. Although it is difficult to disentangle the variation of the EU ETS regulatory framework from the collapse of financial

\footnotetext{
${ }^{28}$ Since we are interested in the general tendency of registries' PageRanks over time, we plot a smoothed version of the results which offers a less erratic representation of registries' trends. In fact, although we use aggregated data on a monthly basis, this is not sufficient to prevent missing values for some nodes; thus, a fitting procedure helps to overcome this issue. In particular, fitting is done locally in the neighbourhood of each value.

${ }^{29}$ We discard data after June 2012 since the low number of active national registries prevents a proper computation of the PageRanks. As already pointed out in Section 2 (see Figure 2 above), in the second half of 2012 the volume of exchanges was marginal compared to previous months and the number of active registries was extremely low being equal to: 1 in September (GB); 2 in July (FR, IT), August (FR, IT), October (GB, IT) and December (ES, IT); 6 in November (CZ, DE, FI, GB, NL, SK).
} 
markets, some interesting findings can be observed by splitting our results over time according to different types of account. For instance, one can investigate how PHAs, which are not regulated entities and are often associated with financial intermediaries, have reacted against the deteriorated market conditions. This leads to the analysis of the PHAs specification (figure on the top-right in the panel). The diagram shows that DK was particularly central during the beginning of Phase I, playing in the PHAs framework a similar role to that of DE in the OHAs case. This is probably due to the fact that DK was one of the first countries to open a registry. Moreover, many firms (including several shell companies) opened PHAs in DK also from countries outside the EU given the lax requirements initially set to open an account in DK. In general, in the PHAs specification the decreasing pattern which affects centrality scores during Phase II is more evident. This trend seems to have accelerated around year 2012, thus pointing to a less central role for these registries. The set of selected registries refers to those countries where financial intermediaries usually open accounts due to the presence of dedicated exchange platforms and/or favourable business conditions; as a consequence, their centrality can be influenced by market players practices. As to the fall in centrality experienced by FR, this seems to reflect the carbon carousel fraud on France's Bluenext exchange occurred in June 2009, which weakened the platform and, ultimately, contributed to its closure at the end of 2012. Indeed, volumes exchanged on the Bluenext's market increased remarkably during the VAT fraud and then collapsed once FR changed its VAT rules in 2009 after the discovery of the fraud (Europol, 2010). Interestingly, the decrease of the PageRank in FR was initially accompanied by an increase in both DK and GB (see the right-top diagram in Figure 5). This might be due to the fact that companies moved from FR to these other countries after the discovery of the VAT fraud. In the following months/years, however, the VAT rules were changed also in these countries, which might explain why DE and GB experienced a fall in centrality with a time lag with respect to FR. This seems consistent with the evidence showing that trading volumes first peaked in FR during the VAT fraud, then also in DE and GB that were particularly impacted by such fraud activities (see e.g. Frunza et al., 2011; Wei, 2015; Wei and Betz, 2016). The last two plots (figures on the bottom in the panel) show the combined effects arising from the inclusion of more types of accounts. The network composed by OHAs and PHAs (figure on the bottom left) reveals centrality scores in line with those reported for the PHAs case. As expected, the role of PHAs influences the overall representation due to the huge number and volumes of transactions. The last plot extends the network to all the account types (figure on the bottom right), showing a general trend that is quite coherent with the previous scenarios. Indeed, even in these specifications we can observe a decreasing pattern in the centrality scores that resembles the one described above for transfers between PHAs only. Interestingly, the switch from Phase I to Phase II coincided with remarkable changes in PageRanks curves for each specification; the approaching to the end of Phase II seems to suggest again a renewed variation in PageRanks which show wider ranges of values across states during the interval around year 2012. Similar findings emerge from the alternative scenario (see Appendix A.6) which introduces a richer set of transactions types, including allowances issue, surrender and allocation.

In Figure 6 we consider how the Assortativity coefficients have evolved over time. This measure indicates how pairs of registries are related in terms of their Strengths. Since the network is directed, this determines four possible cases (In-In, Out-Out, In-Out and Out-In Assortativity coefficients), as a result of combining both source and target nodes with in-flows or out-flows (as presented in subsection 3.1). For the sake of clarity, below we report only the In-In and the Out-Out Assortativity coefficients for the core scenario ${ }^{30}$. In particular, we focus here on the In-In Assortativity coefficients, since the Out-Out Assortativity coefficients exhibit very similar patterns. Values for the OHAs scenario (first figure at the top of the panel) are basically always positive indicating a positive correlation between registries that share common distributions in terms of In-Strength. This is a sign of a positive relationship between pairs of connected nodes in terms of the amount of units being transferred. Hence, there is a preference to form links among registries with similar In-Strength distributions. In other words, nodes tend to be biased in the choice of their trading partners and preferably attach to other nodes with similar connectivity. However, as the figure shows, results for the OHAs case describe a very volatile framework. This erratic behaviour does not seem to reflect any specific regularity linked to end-of-period commitments or seasonal aspects. There are periods in which registries are strictly connected to others with very similar In-Strength distributions (Assortativity pointing to one) and others where the relationship is poorly assortative (coefficient near to zero). The existence of few transactions involving only OHAs is likely to affect this unstable pattern. Conversely, when we analyze the PHAs specification we observe a clear decreasing trend with a peak around the onset of 200708 financial crisis (second figure in the panel). Interestingly, after the collapse of the capital markets the network becomes slightly disassortative, namely, the value of the Assortative coefficient becomes negative, which suggests that nodes tended to connect (i.e. exchange allowances) with more dissimilar counterparts. This is an interesting finding since it means that after 2008, PHAs were more prone to trade with other accounts in a more diversified fashion. Disentangling the effects of the financial crisis from the changes in the regulatory framework (from Phase I to Phase II) goes beyond the scope of this study; however, we can advance a couple of possible reasons to explain the observed trend in the Assortativity coefficient of PHAs. One is related to risk diversification, which induced PHAs to trade with a wider range of accounts, thus limiting deals with counterparts belonging to the same registry or to similar registries (in terms of Strength). A second explanation, which is partially related to the first, concerns the enlargement of the

\footnotetext{
${ }^{30}$ The interested reader can refer to Appendix A.7 and A.8 for the complete set of figures. Results are basically unaffected by the choice of the different specifications of the Assortativity coefficient. We recall that this indicator refers to the Pearson coefficient between pairs of connected nodes with respect to the selected direction of the link.
} 
EU ETS that might have promoted the exploitation of new markets and exchanges between a wider set of counterparts. By facilitating transactions across registries, PHAs may have contributed to include a larger set of registries in the EU ETS functioning, which is in line with the results discussed above indicating an increasing number of active registries in the PHAs case during Phase II (cf. Figure 2). Moreover, if we add together OHAs and PHAs (third figure in the panel), results confirm the same change in sign, thus showing a similar pattern to the one for the PHAs specification. Even for the Assortativity coefficients, the impact of PHAs on the overall picture is, therefore, dominant. Lastly, we consider all the types of account (fourth figure in the panel) and we obtain a slightly more erratic pattern across the two phases, but even in this case the trend turns out to be pretty similar to the ones for PHA and OHA \& PHA cases described above.

Figure 6: Assortativity Coefficients (IN-IN and OUT-OUT). We consider the following specifications (from the first plot on the top): OHAs, PHAs, OHAs \& PHAs, and all types of account under the core scenario (transaction codes: 3-0, 3-21, and 10-0). Blue lines indicate IN-IN Assortativity coefficients, while the green colour refers to OUT-OUT Assortativity coefficients. Source: authors' own elaborations based on the EUTL transactions data set for the first two Phases.

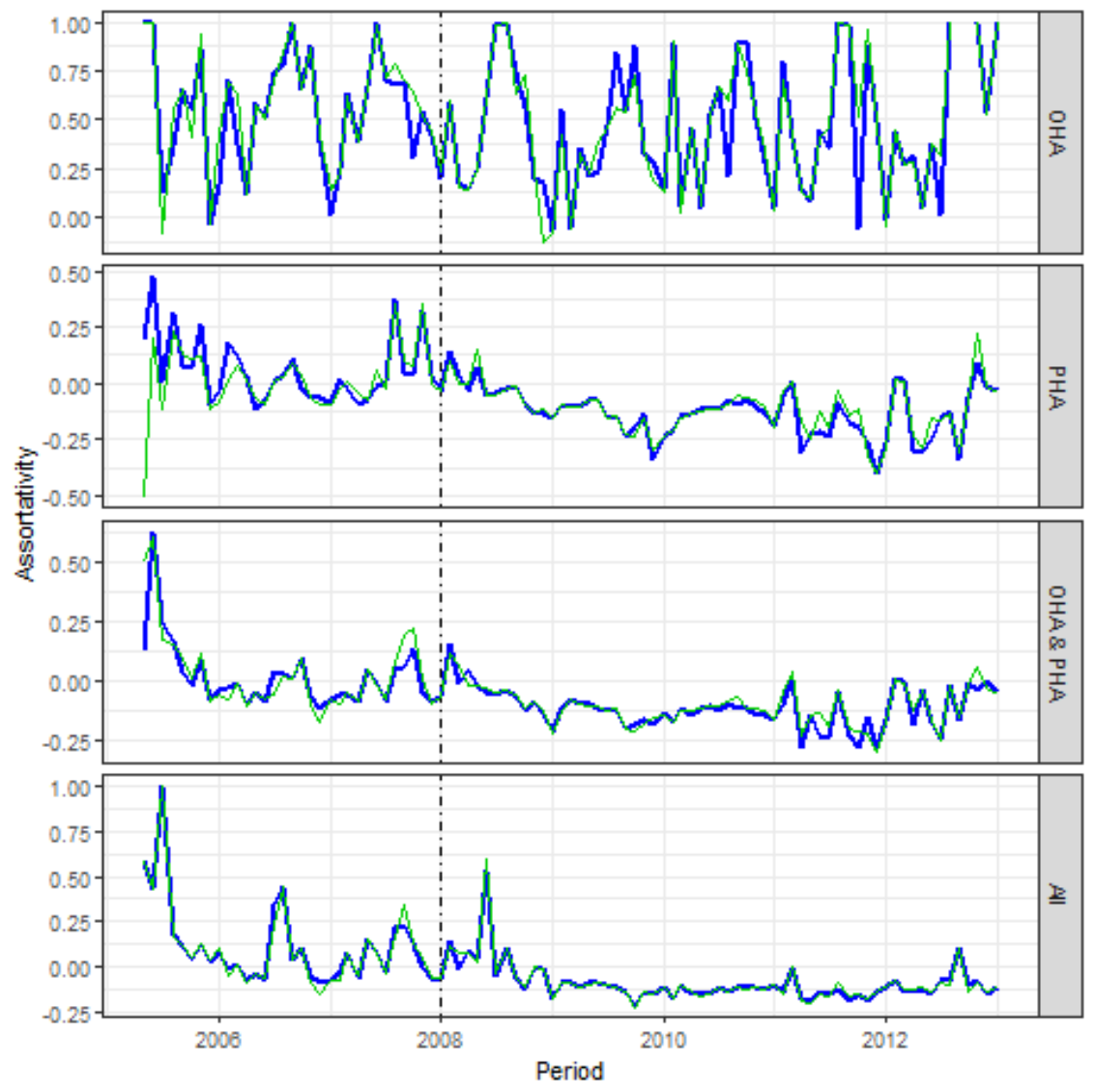

Plots in Figure 7 compare the PageRank for each registry (as reported in Table 3, column $A L L$ ) with the verified emissions for that country retrieved from the European Environment Agency ${ }^{31}$ for both Phase I and Phase II, separately. Correlations between PageRanks and verified emissions are 0.52 and 0.64 for Phase I and Phase II (p-values are lower than 0.01 in both cases), respectively. Centrality of registries seems to be only slightly related to their effective emissions. As emerged from the diagrams, we observe the presence of a bundle of countries with verified emissions below 0.3 Billion t/CO2 which are concentrated in a strict range of low values for PageRanks, from which DK departs towards higher values of centrality (in both phases, although mainly for Phase I). For higher values of verified emissions, Figure 7 shows also the emergence of a club composed by IT, ES and PL (especially in Phase II), that although characterized by high emissions values are not substantially more central compared to the former subset of registries. The diagrams also exhibit a remarkable similarity between FR and NL which is persistent over time and characterized by higher PageRanks than those of IT, ES and PL, although the latter have higher values of verified emissions. Finally, DE and GB present quite peculiar patterns and seem not to have direct peers when both dimensions are jointly considered. The two countries host two key platforms for trading (and in which EU allowances are auctioned in Phase III): the European Energy Exchange (EEX) in Leipzig and the Intercontinental Exchange (ICE) in London. This can contribute to explain their role as outliers that emerges in Figure 7. These findings, together with the ones discussed above, suggest that the trade of allowances may be driven by additional reasons other than simple compliance purposes, determining the very active role of certain

\footnotetext{
${ }^{31}$ Data can be accessed from this website: http://www.eea.europa.eu/data-and-maps/data/data-viewers/emissions-tradingviewer-1. Appendix A.10 shows additional comparisons between PageRanks and the number of acquiring accounts for each registry.
} 
registries. Those registries, that turned out to be more active/central than what expected from the level of verified emissions, may represent countries with more favourable conditions for trading in allowances and, as a consequence, for the location of the accounts. The use of network centrality measures to gauge the presence of very central registries can represent the starting point to shed light on the reasons, other than compliance purposes, behind the emergence of some registries as hubs for the exchange of allowances in the EU ETS.

Figure 7: Comparisons between PageRanks and Verified Emissions. Plots show the correlations between PageRanks and the corresponding values of verified emissions (1 Billion emission unit - CO2); plots refer to Phase I and II, respectively. PageRanks refer to mean values from Table 3, column $A L L$. Verified emissions are retrieved from the European Environment Agency (EEA) and refer to the sum of verified emissions (for all stationary installations) during the corresponding Phase. Source: authors' own elaborations based on the EEA and the EUTL transactions data sets for the first two Phases.
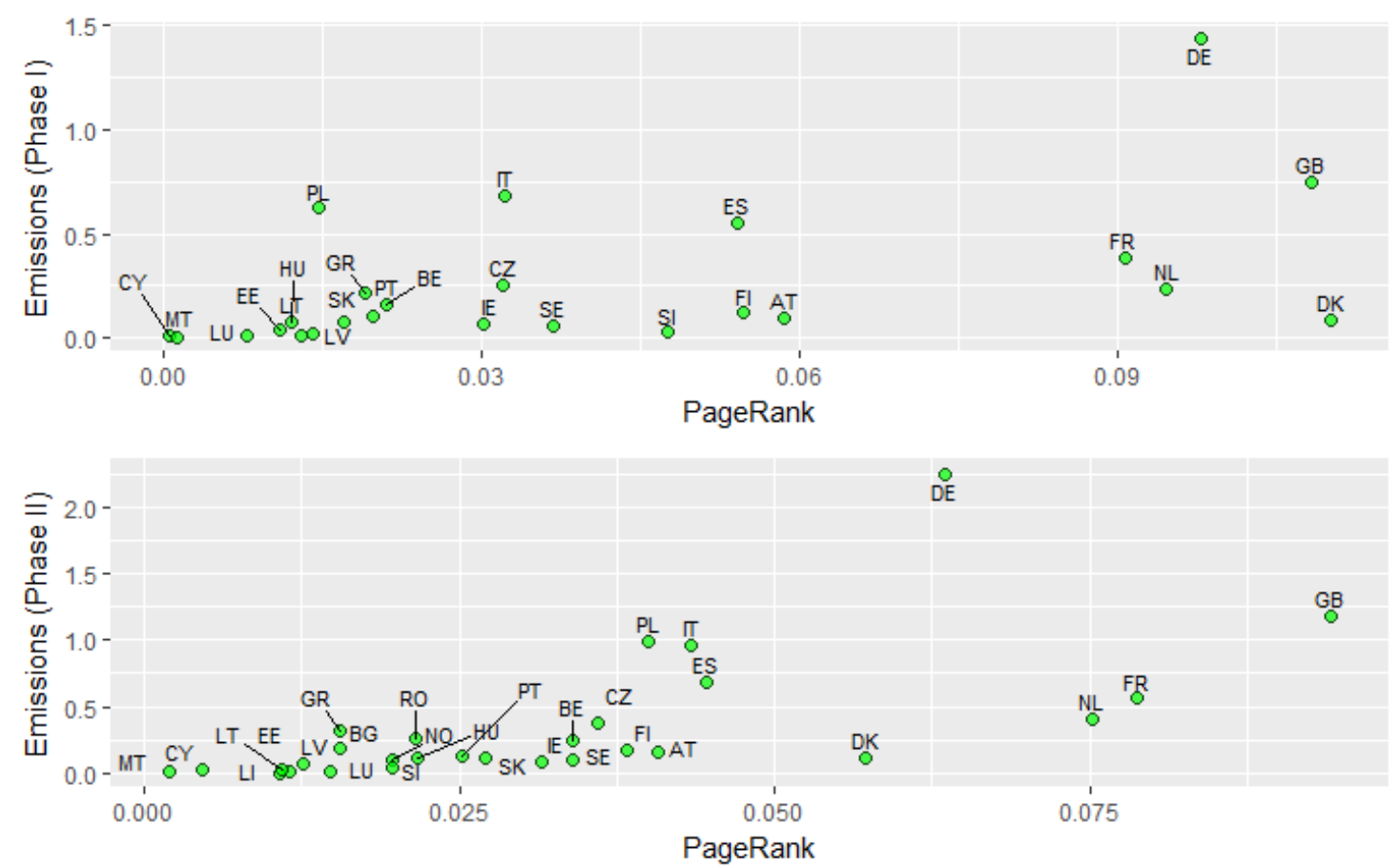

The bundle of nodes on the right of Figure 7 are actually those identified in subsection 2.4 as the ones more affected by inflows of accounts from different countries of origin. Hence, we provide an additional representation of the EU ETS by considering the country of origin instead of the national registry ${ }^{32}$. This further EU ETS facet is aimed to describe how the system would have been under the assumption that accounts are registered in their countries of origin. As already presented above, some PHAs may have opted to open accounts in those Member States which offered more favourable conditions, for instance, in terms of account set up requirements and the presence of dedicated exchange platforms. In addition, some accounts from outside EU countries entered in the EU ETS opening accounts most probably in those states where exchange platforms were active. A comparison between a registry-level and a country-level network analysis is beneficial, therefore, to confirm the attractiveness of certain states and, in turn, to justify their centrality in the EU ETS.

This further specification includes many countries outside EU which are present only in few transactions. For them we basically follow the previous approach and create a comprehensive node named Others ${ }^{33}$. By contrast, the United States ${ }^{34}$ represent a country of origin for many active accounts, therefore, we decided to consider it as a separate node in the network analysis. Table 4 provides a comparison among PageRanks under the country-level vs. registry-level scenarios for different account types specifications. It focuses on those Member States more central in the EU ETS plus the nodes Others and US ${ }^{35}$.

\footnotetext{
${ }^{32}$ We map the EUTL transaction data set with the EUTL account data set by considering the triple (account type, account identifier name, account holder name). We are able to include more than 93 per cent of the transactions present in the core scenario. In particular, we replace the transferring/acquiring registry with the current country specified in the EUTL account data set. In few cases the country field is empty, thus for them we rely on the national registry item.

${ }^{33}$ The Others node includes a wide list of countries often poorly represented: Anguilla, Australia, Bahamas, Barbados, Belize, Bermuda, Brazil, British Virgin Islands, Canada, Cayman Islands, CDM, China, Gibraltar, Hong Kong, India, Indonesia, Israel, Japan, Jersey, Kazakhstan, Lebanon, Malaysia, Mauritius, Mexico, New Zealand, Pakistan, Philippines, Republic of Korea, Russian Federation, Saint Kitts and Nevis, Seychelles, Singapore, South Africa, Taiwan, Thailand, Turkey, Turks and Caicos Islands, and UAE. Together these countries are involved in about 2 per cent of the transferring units and less than 1 per cent of the acquiring permits in the core specification.

${ }^{34}$ In the core specification US accounts are involved as transferring or acquiring counterparts in about 1 per cent and 0.6 per cent of the transferred amount, respectively. We refer to their aggregation as the US node hereinafter.

${ }^{35}$ The complete representation for all countries under the country-level scenario is shown in Appendix A.9.
} 
Results in Table 4 indicate that, as expected, there are no substantial differences under the OHAs case, while some remarkable discrepancies arise once we consider PHAs alone or in combination with the other account types. For DE, IT and ES these differences are modest, with similar centrality scores under both the country-level and registry-level. By contrast, in some cases we note some evident reductions in terms of centrality when the country of origin is considered instead of the national registry. This is the case of AT, DK, and NL which became less central in every account type specification. However, other states like $\mathrm{BE}, \mathrm{CH}$ and GB show the opposite pattern, reaching higher values of PageRank under the country-level representation. Moreover, we observe that once again the centrality rankings of the specification where all the types of accounts are included are strongly influenced by the role of PHAs, being the PageRanks for only PHAs quite similar to those for the ALL case. Finally, we also notice that node Others remains peripheral despite the enlargement of the geographical coverage, while PHAs from US would have had a mild centrality if grouped with respect to their country of origin.

Table 4: Network Statistics: Comparison between Country-level vs. Registry-level. Table shows PageRank values for both the Country-level and the Registry-level. We show different specifications according to specific subsets of account types: OHA, PHA, OHA \& PHA, OHA \& PHA \& HA, and all types of accounts, respectively. We report mean values for Phase I and Phase II of the EU ETS program and for the overall sample period (in bold). We consider the transaction types: 3-0, 3-21, and 10-0. Source: authors' own elaborations based on the EUTL transactions data set for the first two Phases.

\begin{tabular}{|c|c|c|c|c|c|c|c|c|c|c|}
\hline & \multicolumn{2}{|c|}{ OHA } & \multicolumn{2}{|c|}{ PHA } & \multicolumn{2}{|c|}{ OHA \& PHA } & \multicolumn{2}{|c|}{ OHA \& PHA \& HA } & \multicolumn{2}{|c|}{ ALL } \\
\hline & Country & Registry & Country & Registry & Country & Registry & Country & Registry & Country & Registry \\
\hline Austria (AT) & 0,04 & 0,04 & 0,04 & 0,04 & 0,04 & 0,05 & 0,04 & 0,04 & 0,04 & 0,05 \\
\hline Phase I & 0,01 & 0,01 & 0,04 & 0,06 & 0,04 & 0,05 & 0,04 & 0,05 & 0,04 & 0,06 \\
\hline Phase II & 0,06 & 0,06 & 0,03 & 0,04 & 0,04 & 0,05 & 0,04 & 0,04 & 0,04 & 0,04 \\
\hline Belgium (BE) & 0,04 & 0,04 & 0,04 & 0,02 & 0,05 & 0,04 & 0,05 & 0,03 & 0,05 & 0,03 \\
\hline Phase I & 0,04 & 0,04 & 0,06 & 0,01 & 0,07 & 0,02 & 0,06 & 0,02 & 0,06 & 0,02 \\
\hline Phase II & 0,04 & 0,05 & 0,04 & 0,03 & 0,04 & 0,04 & 0,04 & 0,04 & 0,04 & 0,03 \\
\hline Denmark (DK) & 0,06 & 0,06 & 0,03 & 0,10 & 0,03 & 0,08 & 0,03 & 0,08 & 0,03 & 0,08 \\
\hline Phase I & 0,06 & 0,06 & 0,05 & 0,15 & 0,04 & 0,11 & 0,04 & 0,11 & 0,04 & 0,11 \\
\hline Phase II & 0,06 & 0,06 & 0,03 & 0,07 & 0,03 & 0,06 & 0,03 & 0,06 & 0,03 & 0,06 \\
\hline France $(F R)$ & 0,07 & 0,07 & 0,12 & 0,10 & 0,09 & 0,09 & 0,09 & 0,09 & 0,09 & 0,08 \\
\hline Phase I & 0,04 & 0,04 & 0,13 & 0,11 & 0,09 & 0,09 & 0,09 & 0,09 & 0,09 & 0,09 \\
\hline Phase II & 0,09 & 0,09 & 0,11 & 0,09 & 0,09 & 0,09 & 0,09 & 0,08 & 0,09 & 0,08 \\
\hline Germany (DE) & 0,13 & 0,13 & 0,09 & 0,10 & 0,08 & 0,08 & 0,08 & 0,08 & 0,08 & 0,08 \\
\hline Phase I & 0,22 & 0,22 & 0,11 & 0,12 & 0,10 & 0,10 & 0,10 & 0,10 & 0,10 & 0,10 \\
\hline Phase II & 0,09 & 0,09 & 0,08 & 0,08 & 0,07 & 0,07 & 0,07 & 0,07 & 0,07 & 0,06 \\
\hline Italy (IT) & 0,06 & 0,06 & 0,04 & 0,04 & 0,04 & 0,04 & 0,04 & 0,04 & 0,04 & 0,04 \\
\hline Phase I & 0,07 & 0,07 & 0,03 & 0,03 & 0,03 & 0,03 & 0,03 & 0,03 & 0,03 & 0,03 \\
\hline Phase II & 0,05 & 0,05 & 0,05 & 0,05 & 0,04 & 0,04 & 0,04 & 0,04 & 0,04 & 0,04 \\
\hline Netherlands (NL) & 0,04 & 0,04 & 0,06 & 0,09 & 0,06 & 0,08 & 0,06 & 0,08 & 0,06 & 0,08 \\
\hline Phase I & 0,06 & 0,06 & 0,07 & 0,11 & 0,07 & 0,10 & 0,07 & 0,10 & 0,07 & 0,09 \\
\hline Phase II & 0,03 & 0,03 & 0,06 & 0,08 & 0,06 & 0,07 & 0,06 & 0,08 & 0,06 & 0,08 \\
\hline Others & 0,00 & 0,00 & 0,02 & 0,00 & 0,01 & 0,00 & 0,02 & 0,02 & 0,02 & 0,02 \\
\hline Phase I & 0,00 & & 0,00 & & 0,01 & & 0,01 & & 0,01 & \\
\hline Phase II & 0,00 & 0,00 & 0,02 & 0,00 & 0,02 & 0,00 & 0,03 & 0,02 & 0,03 & 0,02 \\
\hline Spain (ES) & 0,07 & 0,07 & 0,06 & 0,07 & 0,05 & 0,06 & 0,05 & 0,05 & 0,05 & 0,05 \\
\hline Phase I & 0,05 & 0,04 & 0,07 & 0,07 & 0,06 & 0,05 & 0,06 & 0,06 & 0,06 & 0,05 \\
\hline Phase II & 0,09 & 0,09 & 0,06 & 0,07 & 0,05 & 0,06 & 0,04 & 0,05 & 0,04 & 0,04 \\
\hline Switzerland $(\mathrm{CH})$ & 0,00 & 0,00 & 0,03 & 0,00 & 0,03 & 0,00 & 0,05 & 0,03 & 0,05 & 0,03 \\
\hline Phase I & 0,00 & & 0,04 & & 0,04 & & 0,04 & & 0,04 & \\
\hline Phase II & 0,00 & 0,00 & 0,03 & 0,00 & 0,03 & 0,00 & 0,05 & 0,03 & 0,05 & 0,03 \\
\hline United Kingdom (GB) & 0,07 & 0,07 & 0,12 & 0,12 & 0,11 & 0,10 & 0,10 & 0,10 & 0,10 & 0,10 \\
\hline Phase I & 0,10 & 0,10 & 0,14 & 0,12 & 0,13 & 0,11 & 0,13 & 0,11 & 0,13 & 0,11 \\
\hline Phase II & 0,05 & 0,05 & 0,11 & 0,11 & 0,09 & 0,10 & 0,09 & 0,10 & 0,09 & 0,09 \\
\hline United States (US) & 0,00 & & 0,02 & & 0,02 & & 0,03 & & 0,03 & \\
\hline Phase I & 0,00 & & 0,02 & & 0,02 & & 0,02 & & 0,02 & \\
\hline Phase II & 0,00 & & 0,03 & & 0,02 & & 0,03 & & 0,03 & \\
\hline
\end{tabular}

The country-level exercise confirms the relevant role of accounts joining a different national registry than the location country. For some Member States the centrality scores appear very stable under the two scenarios, while significant differences arise for some of those nodes very active in the registry-level configuration. This is clearly the case of DK and NL which experienced a remarkable drop in their centrality once the country of origin is considered. By contrast, states which host dedicated exchange platforms confirm their key role in the EU ETS in both country-level and registry-level scenarios (e.g., DE, FR, and GB). Hence, it seems useful to distinguish the way these states became very central in the system, suggesting to differentiate for instance between more favourable account set up requirements and the presence of exchange platforms. Finally, these differences appear stronger during Phase I, supporting also the idea that during the early stage of the EU ETS these states were more able to attract accounts from the other Member States due to their comparative advantages in terms of market infrastructure and conditions. A more mature system which seems to emerge in Phase II points to a common playing field, where the presence of few and very central hubs is nuanced.

Finally, we outline a specification of the PHA perimeter more focused on non-regulated entities. In fact, OHAs and PHAs may share the same control structure and, therefore, refer to a common owner. This is particularly relevant for very active players, for instance those in the energy and power generation fields, who manage both OHAs for their installations and a battery of PHAs for trading purposes. In EUTL jargon, it means that the same holding account is related to many account identifiers belonging to different account types (e.g., OHAs and PHAs). This calls for the separation between two groups of PHAs: related and unrelated to OHAs (i.e. that are/aren't directly part of a corporate which includes OHAs). Moreover, the PHAs sample is highly influenced by transactions which involve financial institutions. Therefore, we introduce an additional facet with the aim to approximate the role of those PHAs referring to financial 
accounts only. Table 5 shows the results on PageRanks circumscribed to: (i) accounts indicated as PHAs in the EUTL (see also Table 3), (ii) PHAs without related OHAs, and (iii) PHAs related to financial institutions. In particular, PHAs without related OHAs are computed by excluding those PHAs which refer to holding accounts that have also OHAs. In the interval 2005-12 we have about $10.5 \mathrm{k}$ holding accounts in sample (i), which drop to about $3 \mathrm{k}$ for sample (ii) once we remove those accounts that are also related to OHAs. This number further reduces to $1.1 \mathrm{k}$ holding accounts when we focus on the subset of PHAs related to financial institutions (sample iii). The latter is obtained by matching PHAs without related OHAs to the Orbis database provided by Bureau van Dijk referred to financial entities ${ }^{36}$. Results of Table 5 show modest differences among PageRanks computed within the PHAs perimeter and those circumscribed to PHAs not related to OHAs (we focus on a subset of relevant national registries). Transactions involving PHAs not related to OHAs represent, in particular, about 85 per cent of the total transferred amount between PHAs only. As to the role of PHAs related to financial institutions, we observe that they are responsible for about 34 per cent of the amount transferred by PHAs only. Even in this case, the centrality scores are in general coherent with the other aforementioned PHAs specifications, although for those national registries usually associated to relevant financial markets (e.g., DE, FR, GB, and NL) PageRanks values are higher, thus denoting a more active role. This finding supports the interpretation that the active role of PHAs is mainly driven by accounts not directly subject to the EU ETS.

Table 5: Network Statistics: Comparison between PHAs specifications. Table shows PageRank values for PHAs, PHAs without related OHAs, and PHAs related to financial institutions. PHAs without related OHAs are computed excluding PHAs that refer to holding accounts which own also OHAs; PHAs related to financial institutions match the latter to the Orbis database referred to financial entities. We report mean values for Phase I and Phase II of the EU ETS program and for the overall sample period (in bold). We consider only transactions between PHAs (as defined above) and with transaction types: 3-0, 3-21, and 10-0. We focus on a subset of national registries. Source: authors' own elaborations based on the EUTL transactions data set for the first two Phases.

\begin{tabular}{|c|c|c|c|c|c|c|}
\hline \multirow[b]{3}{*}{ Austria (AT) } & \multicolumn{2}{|c|}{ PHA } & \multicolumn{2}{|c|}{ PHA (no OHA) } & \multicolumn{2}{|c|}{ PHA (financials) } \\
\hline & mean & sd & mean & sd & mean & sd \\
\hline & 0,04 & $2,35 \%$ & 0,04 & $2,33 \%$ & 0,05 & $3,92 \%$ \\
\hline Phase I & 0,06 & $3,25 \%$ & 0,06 & $3,22 \%$ & 0,05 & $5,03 \%$ \\
\hline Phase II & 0,04 & $1,86 \%$ & 0,04 & $1,84 \%$ & 0,05 & $3,31 \%$ \\
\hline Belgium (BE) & 0,02 & $3,22 \%$ & 0,03 & $4,05 \%$ & 0,01 & $1,71 \%$ \\
\hline Phase I & 0,01 & $0,94 \%$ & 0,01 & $1,21 \%$ & 0,00 & $0,71 \%$ \\
\hline Phase II & 0,03 & $4,47 \%$ & 0,04 & $5,61 \%$ & 0,02 & $2,27 \%$ \\
\hline Denmark (DK) & 0,10 & $6,83 \%$ & 0,09 & $7,03 \%$ & 0,08 & $5,99 \%$ \\
\hline Phase I & 0,15 & $10,41 \%$ & 0,15 & $9,81 \%$ & 0,10 & $5,67 \%$ \\
\hline Phase II & 0,07 & $4,85 \%$ & 0,07 & $5,50 \%$ & 0,07 & $6,17 \%$ \\
\hline France $(F R)$ & 0,10 & $4,10 \%$ & 0,11 & $6,29 \%$ & 0,18 & $9,74 \%$ \\
\hline Phase I & 0,11 & $5,14 \%$ & 0,15 & $10,43 \%$ & 0,22 & $13,60 \%$ \\
\hline Phase II & 0,09 & $3,52 \%$ & 0,10 & $4,01 \%$ & 0,15 & $7,62 \%$ \\
\hline Germany (DE) & 0,10 & $4,33 \%$ & 0,09 & $4,72 \%$ & 0,11 & $5,42 \%$ \\
\hline Phase I & 0,12 & $4,58 \%$ & 0,12 & $5,38 \%$ & 0,13 & $5,78 \%$ \\
\hline Phase II & 0,08 & $4,19 \%$ & 0,08 & $4,36 \%$ & 0,10 & $5,22 \%$ \\
\hline Greece (GR) & 0,01 & $0,90 \%$ & 0,01 & $0,75 \%$ & 0,01 & $1,31 \%$ \\
\hline Phase I & 0,00 & $0,58 \%$ & - & - & - & - \\
\hline Phase II & 0,01 & $1,08 \%$ & 0,01 & $1,16 \%$ & 0,01 & $2,02 \%$ \\
\hline Ireland (IE) & 0,02 & $0,98 \%$ & 0,02 & $1,09 \%$ & 0,01 & $1,55 \%$ \\
\hline Phase I & 0,01 & $1,11 \%$ & 0,01 & $1,20 \%$ & 0,01 & $1,65 \%$ \\
\hline Phase II & 0,02 & $0,91 \%$ & 0,02 & $1,03 \%$ & 0,02 & $1,49 \%$ \\
\hline Italy $(I T)$ & 0,04 & $4,56 \%$ & 0,05 & $5,56 \%$ & 0,03 & $2,21 \%$ \\
\hline Phase I & 0,03 & $3,02 \%$ & 0,03 & $4,17 \%$ & 0,01 & $1,03 \%$ \\
\hline Phase II & 0,05 & $5,41 \%$ & 0,06 & $6,33 \%$ & 0,04 & $2,85 \%$ \\
\hline Netherlands (NL) & 0,09 & $2,76 \%$ & 0,09 & $3,01 \%$ & 0,12 & $5,58 \%$ \\
\hline Phase I & 0,11 & $3,09 \%$ & 0,11 & $3,80 \%$ & 0,14 & $7,70 \%$ \\
\hline Phase II & 0,08 & $2,58 \%$ & 0,08 & $2,58 \%$ & 0,10 & $4,42 \%$ \\
\hline Spain (ES) & 0,07 & $4,77 \%$ & 0,05 & $3,54 \%$ & 0,03 & $2,48 \%$ \\
\hline Phase I & 0,07 & $7,08 \%$ & 0,04 & $5,26 \%$ & 0,01 & $1,71 \%$ \\
\hline Phase II & 0,07 & $3,49 \%$ & 0,06 & $2,60 \%$ & 0,03 & $2,90 \%$ \\
\hline United Kingdom (GB) & 0,12 & $3,94 \%$ & 0,12 & $4,12 \%$ & 0,15 & $6,75 \%$ \\
\hline Phase I & 0,12 & $5,05 \%$ & 0,13 & $5,37 \%$ & 0,14 & $7,66 \%$ \\
\hline Phase II & 0,11 & $3,33 \%$ & 0,11 & $3,43 \%$ & 0,16 & $6,25 \%$ \\
\hline
\end{tabular}

\section{Conclusions}

The EU ETS has attracted increasing attention among scholars and policy makers in the last decade. Despite the ever-growing literature on this system, little attention has been devoted so far to providing a detailed analysis of the transactions in the EU ETS and of the resulting market structure. In order to fill this gap of the literature the present paper tries to enrich the observation of the EU ETS in several respects: extending the analysis in inter-temporal terms so as to cover not only Phase I but also Phase II; enlarging the data set to include additional account types; aggregating data at national registry level to investigate the role of Member States in the EU ETS.

Differently from previous contributions, moreover, we attempt to describe the EU ETS from a novel perspective using Network Theory tools. This approach allows to provide a more comprehensive point of

\footnotetext{
${ }^{36}$ We consider banks, insurance companies and other financial institutions.
} 
view on the structure of the system. For instance, to identify which countries have been more central, rather than a simple computation of each country's total in-flows or out-flows, we propose the use of the PageRank, a measure of eigenvector centrality that accounts not only for the single registry's flows but also for the impact of its neighbourhood, thus enriching the investigation of the key players in the EU ETS. Furthermore, the structure of the network can be analyzed by means of its topological properties. Here, we exploit the Assortativity coefficient that in our opinion is particularly suitable for the present introductory investigation since it is a quite intuitive measure given its similarity with the Pearson Correlation. Using these Network measures, the paper tries to investigate the following three main questions: (i) which national registries have been more central in the EU ETS? (ii) how many account holders moved from their country of origin to a different national registry and where did they moved to/from? (iii) which account types have played a dominant role in the system? (iv) what has been the evolution of the market structure during the first two phases?

To address these issues, we analyze a wide set of transactions from February 2005 until December 2012, thus covering Phase I and Phase II. We investigate the structure of the EU ETS from several specifications, distinguishing between internal and external transactions as well as between different types of accounts: Holding Accounts (HAs), Pending Accounts (PAs), Operator Holding Accounts (OHAs), Person Holding Accounts (PHAs) as well as a set of counterparts for which this information is not fully available (NAs).

From the analysis performed in the paper, the following answers emerge to the research questions indicated above. As to the 1st issue, centrality measures show the presence of a core of central nodes (FR, DE, GB, DK, NL) surrounded by a periphery of marginal registries, with some countries that still remain less central in the system even during Phase II. To address the 2 nd issue, we repeated the analysis considering the country of origin of the account holders instead of the national registry where they opened their accounts. Results show that most moving accounts migrated towards the central nodes described above, particularly towards Denmark, United Kingdom and France (though the latter only in Phase I before the discovery of the VAT fraud on the BlueNext platform). These migrations - that may have been driven by multiple reasons (e.g. fiscal advantages, dedicated exchange platforms, less stringent requirements to open a new account etc...) - have affected the structure of the network, making some countries more (less) central than what they would have otherwise appeared. As to the 3rd question, descriptive statistics suggest the emergence of the dominant impact of the PHAs, that are characterized by the significant presence of financial sector intermediaries. This confirms also for Phase II what was found by Betz and Schmidt (2016) for Phase I. Many regulated companies might have opened a PHA to trade or just to have an account in the foreign registry in which the exchange is located. Therefore, to get a deeper understanding on the role of the intermediaries compared to that of regulated companies, we repeated the analysis focusing on the subset of PHAs opened by unregulated companies and, more specifically, by financial intermediaries. Results are in line with those obtained for the whole set of PHAs (including both regulated and unregulated PHAs), which seems to confirm the dominant role played by unregulated entities in general, and financial intermediaries in particular. Thus, transactions were not done for compliance purposes only, but reflected the role of players voluntarily participating in the EU ETS (e.g. banks, financial intermediaries, and brokers). As to the 4th question, the system has become progressively more homogeneous (with less central nodes) and tended to diversify trading partners (as suggested by the observed declining assortativity) as it moved from Phase I to Phase II.

In our opinion, the approach adopted in this work can provide interesting insights on the structure of the EU ETS that can be easily adapted and enriched in the future, applying the same methodology at installation, firm or parent-company levels, thus showing other perspectives. For instance, one could analyze which sectors are more active (central) in the EU ETS and how they are related. In addition, this approach could be used to provide a study on the size and regional distributions of the accounts. Furthermore, community detection approaches are highly recommended to identify clusters of players that share similar features. More importantly, a deeper analysis should involve PHAs. Most of them belong to the financial sector and we know that these actors play several fundamental roles in the system, e.g. facilitate the trading of smaller players, provide liquidity to the market and create derivatives instruments to manage market risk. On the other hand, financial intermediaries even act as speculative actors to generate profits inducing volatility into the market, which might determine instability for OHAs that trade for compliance purposes. Therefore, to assess the possible trade-off generated from the inclusion in the EU ETS of financial sector's PHAs, the EUTL data should be combined with price data in order to disentangle the role of the different actors involved in the transaction of permits. Moreover, the new requirements introduced by the Markets in Financial Instruments Directive (MiFID) might have affected the role of financial sector's PHAs. Further research, therefore, should analyze the combined impacts of the different regulations affecting this field to provide useful hints to policy-makers on the optimal mix and design of such regulations.

Finally, the methodology adopted here could be used to analyze the structure of the network that might emerge from possible linking agreements with other ETS in the future, an option that is gaining increasing attention among scholars and policy-makers. In fact, following the decision of California and Quebec to link their own ETS by mutually recognizing their allowances, the EU is expected to achieve similar agreements with other ETS in the years to come and negotiations are currently under way with several alternative partners for this purpose. In this regard, Network Theory tools might turn out to be particularly useful to understand the role that single EU Member States might play in a similar new setting and which countries would play a central role in case of linking agreements with different partners. 


\section{Acknowledgement}

The Authors would like to thank two anonymous referees and seminar and conference participants at the University of East Anglia, at the Second EUI Annual Climate Conference on the Economic Assessment of European Climate Policies (European University Institute, Florence), at the Final Workshop of the European Project Fessud (University of Siena), at the 57th Annual conference of the Italian Economists Society (University Bocconi, Milan), and at the 22nd Annual conference of the European Association of Environmental and Resource Economists (Zurich) for their useful comments and suggestions on preliminary versions of the paper. The Authors gratefully acknowledge financial support by MIUR (Italian Ministry of Education, University and Research) for the PRIN National Research Project (prot. 2010S2LHSE).

\section{References}

Abrell, J., A. Ndoye Faye, and G. Zachmann (2011). Assessing the impact of the EU ETS using firm level data. Tech. rep. Bruegel working paper.

Aghion, P., R. Veugelers, and C. Serre (2009). Cold start for the green innovation machine. Tech. rep. Bruegel policy contribution.

Agryzkov, T., J. L. Oliver, L. Tortosa, and J. F. Vicent (2012). "An algorithm for ranking the nodes of an urban network based on the concept of PageRank vector". In: Applied Mathematics and Computation 219.4, pp. 2186-2193.

Alberola, E., J. Chevallier, and B. Chèze (2008). "Price drivers and structural breaks in European carbon prices 2005-2007". In: Energy policy 36.2, pp. 787-797.

Anderson, B. and C. Di Maria (2011). "Abatement and Allocation in the Pilot Phase of the EU ETS". In: Environmental and Resource Economics 48.1, pp. 83-103.

Anger, N. (2008). "Emissions trading beyond Europe: Linking schemes in a post-Kyoto world". In: Energy Economics 30.4, pp. 2028-2049.

Battiston, S., M. Puliga, R. Kaushik, P. Tasca, and G. Caldarelli (2012). "Debtrank: Too central to fail? financial networks, the fed and systemic risk". In: Scientific reports 2, p. 541.

Bel, G. and S. Joseph (2015). "Emission abatement: Untangling the impacts of the EU ETS and the economic crisis". In: Energy Economics 49, pp. 531-539.

Berkhin, P. (2005). "A survey on pagerank computing". In: Internet Mathematics 2.1, pp. 73-120.

Betz, R. A. and T. S. Schmidt (2016). "Transfer patterns in Phase I of the EU Emissions Trading System: a first reality check based on cluster analysis". In: Climate Policy 16.4, pp. 474-495.

Bianchini, M., M. Gori, and F. Scarselli (2005). "Inside pagerank". In: ACM Transactions on Internet Technology (TOIT) 5.1, pp. 92-128.

Borghesi, S., G. Cainelli, and M. Mazzanti (2015). "Linking emission trading to environmental innovation: evidence from the Italian manufacturing industry". In: Research Policy 44.3, pp. 669683.

Borghesi, S., M. Montini, and A. Barreca (2016). The European Emission Trading System and Its Followers: Comparative Analysis and Linking Perspectives. Springer.

Calel, R. and A. Dechezlepretre (2016). "Environmental policy and directed technological change: evidence from the European carbon market". In: Review of economics and statistics 98.1, pp. 173191.

Chevallier, J. (2011). Econometric analysis of carbon markets: the European Union emissions trading scheme and the clean development mechanism. Springer Science \& Business Media.

Cló, S. (2009). "The effectiveness of the EU emissions trading scheme". In: Climate Policy 9.3, pp. $227-241$.

De Perthuis, C. and R. Trotignon (2014). "Governance of CO 2 markets: lessons from the EU ETS". In: Energy Policy 75, pp. 100-106.

Deutsche Emissionshandelsstelle (DEHSt) (2015). Emission Certificates: Updated Version for the EU Trading Period and the Kyoto Commitment Period 2013-2020. Tech. rep. Umwelt Bundesamt.

Doda, B. and L. Taschini (2017). "Carbon dating: When is it beneficial to link ETSs?" In: Journal of the Association of Environmental and Resource Economists 4.3, pp. 701-730.

Edenhofer, O., B. Normark, and B. Tardieu (2014). "Euro-CASE policy position paper". In: Reform Options for the European Emissions.

Ellerman, A. D. and B. K. Buchner (2008). "Over-allocation or abatement? A preliminary analysis of the EU ETS based on the 2005-06 emissions data". In: Environmental and Resource Economics 41.2 , pp. $267-287$.

Ellerman, A. D., F. J. Convery, and C. De Perthuis (2010). Pricing carbon: the European Union emissions trading scheme. Cambridge University Press. 
Ellerman, A. D., C. Marcantonini, and A. Zaklan (2016). "The European union emissions trading system: ten years and counting". In: Review of Environmental Economics and Policy 10.1, pp. 89107.

Engels, A., L. Knoll, and M. Huth (2008). "Preparing for the 'real'market: National patterns of institutional learning and company behaviour in the European Emissions Trading Scheme (EU ETS)". In: Environmental Policy and Governance 18.5, pp. 276-297.

Ermann, L. and D. L. Shepelyansky (2011). "Google matrix of the world trade network". In: arXiv preprint arXiv:1103.502\%.

European Commission (2015). EU ETS Handbook. Tech. rep. Umwelt Bundesamt.

European Parliament and Council of the European Union (2018). Directive (EU) 2018/410 of the European Parliament and of the Council of 14 March 2018 amending Directive 2003/87/EC to enhance cost-effective emission reductions and low-carbon investments, and Decision (EU) 2015/1814. Tech. rep. Official Journal of the European Union, 19/3/2018.

Europol (2010). Further investigations into VAT fraud linked to the carbon emissions trading system. Tech. rep. Europol.

Fabra, N. and M. Reguant (2014). "Pass-through of emissions costs in electricity markets". In: The American Economic Review 104.9, pp. 2872-2899.

Fan, Y., Y.-P. Liu, and J.-F. Guo (2016). "How to explain carbon price using market microbehaviour?" In: Applied Economics 48.51, pp. 4992-5007.

Frunza, M.-C., D. Guegan, and A. Lassoudiere (2011). "Missing trader fraud on the emissions market". In: Journal of financial crime 18.2, pp. 183-194.

Gronwald, M. and B. Hintermann (2015). Emissions trading as a policy instrument: evaluation and prospects. Mit Press.

Halu, A., R. J. Mondragón, P. Panzarasa, and G. Bianconi (2013). "Multiplex pagerank". In: PloS one 8.10, e78293.

Hautsch, N., J. Schaumburg, and M. Schienle (2014). "Financial network systemic risk contributions". In: Review of Finance, pp. 685-738.

Hepburn, C., K. Neuhoff, W. Acworth, D. Burtraw, and F. Jotzo (2016). "The economics of the EU ETS market stability reserve". In: Journal of Environmental Economics and Management 80, pp. $1-5$.

Hoffmann, V. H. (2007). "Eu ets and investment decisions:: The case of the german electricity industry". In: European Management Journal 25.6, pp. 464-474.

Jackson, M. O. (2010). Social and economic networks. Princeton university press.

Jaraite, J., T. Jong, A. Kazukauskas, A. Zaklan, and A. Zeitlberger (2013a). "Ownership Links and Enhanced EUTL Dataset". In: European University Institute, Florence.

Jaraitė, J., T. Jong, A. Kažukauskas, A. Zaklan, and A. Zeitlberger (2013b). "Matching EU ETS Accounts to Historical Parent Companies A Technical Note". In: European University Institute, Florence 18.

Koch, N., S. Fuss, G. Grosjean, and O. Edenhofer (2014). "Causes of the EU ETS price drop: Recession, CDM, renewable policies or a bit of everything?-New evidence". In: Energy Policy 73, pp. 676-685.

Koch, N., G. Grosjean, S. Fuss, and O. Edenhofer (2016). "Politics matters: Regulatory events as catalysts for price formation under cap-and-trade". In: Journal of Environmental Economics and Management 78, pp. 121-139.

Kollenberg, S. and L. Taschini (2016). "Emissions trading systems with cap adjustments". In: Journal of Environmental Economics and Management 80, pp. 20-36.

Kossoy, A., P. Guigon, et al. (2010). State and trends of the carbon market 2012. Tech. rep. The World Bank.

Kwak, H., C. Lee, H. Park, and S. Moon (2010). "What is Twitter, a social network or a news media?" In: Proceedings of the 19th international conference on World wide web. ACM, pp. 591600.

Laing, T., M. Sato, M. Grubb, and C. Comberti (2014). "The effects and side-effects of the EU emissions trading scheme". In: Wiley Interdisciplinary Reviews: Climate Change 5.4, pp. 509519.

Linacre, N., A. Kossoy, P. Ambrosi, et al. (2011). State and trends of the carbon market 2011. Tech. rep. The World Bank.

Liu, Y.-P., J.-F. Guo, and Y. Fan (2017). "A big data study on emitting companies' performance in the first two phases of the European Union Emission Trading Scheme". In: Journal of Cleaner Production 142, pp. 1028-1043. 
Löschel, A., K. L. Brockmann, P. Heindl, B. Lutz, and J. Schumacher (2011). KfW/ZEW CO2 Barometer 2011: Hoher Anpassungsbedarf im EU-Emissionshandel ab 2013-deutliche Defizite bei der Vorbereitung in den Unternehmen. Tech. rep. KfW/ZEW CO2 Barometer.

Löschel, A. et al. (2010). KfW/ZEW CO2 Barometer 2010: Effizienzpotenziale des Emissionshandels noch nicht ausgeschöpt-Strategien und management deutscher Unternehmen. Tech. rep. KfW/ZEW CO2 Barometer.

Martin, R., M. Muûls, L. B. de Preux, and U. Wagner (2014a). "Industry compensation under relocation risk: A firm-level analysis of the EU emissions trading scheme". In: The American Economic Review 104.8, pp. 2482-2508.

Martin, R., M. Muûls, L. B. de Preux, and U. J. Wagner (2014b). "On the empirical content of carbon leakage criteria in the EU Emissions Trading Scheme". In: Ecological Economics 105, pp. $78-88$.

Martin, R., M. Muûls, and U. Wagner (2013). "Carbon markets, carbon prices and innovation: Evidence from interviews with managers". In: Annual Meetings of the American Economic Association, San Diego.

Martin, R., M. Muûls, and U. J. Wagner (2016). "The Impact of the European Union Emissions Trading Scheme on Regulated Firms: What Is the Evidence after Ten Years?" In: Review of Environmental Economics and Policy 10.1, pp. 129-148.

Medina, V., Á. Pardo, and R. Pascual (2014). "The timeline of trading frictions in the European carbon market". In: Energy Economics 42, pp. 378-394.

Newman, M. E. (2002). "Assortative mixing in networks". In: Physical review letters 89.20, p. 208701.

- (2003). "The structure and function of complex networks". In: SIAM review 45.2, pp. 167-256.

Oestreicher-Singer, G. and A. Sundararajan (2012). "Recommendation Networks and the Long Tail of Electronic Commerce". In: MIS Quarterly 36.1.

Pinkse, J. and A. Kolk (2007). "Multinational Corporations and Emissions Trading:: Strategic Responses to New Institutional Constraints". In: European Management Journal 25.6, pp. 441452.

Ranson, M. and R. N. Stavins (2016). "Linkage of greenhouse gas emissions trading systems: Learning from experience". In: Climate Policy 16.3, pp. 284-300.

Rogge, K. S., M. Schneider, and V. H. Hoffmann (2011). "The innovation impact of the EU Emission Trading System-Findings of company case studies in the German power sector". In: Ecological Economics 70.3, pp. 513-523.

Schmidt, T. S., M. Schneider, K. S. Rogge, M. J. Schuetz, and V. H. Hoffmann (2012). "The effects of climate policy on the rate and direction of innovation: A survey of the EU ETS and the electricity sector". In: Environmental Innovation and Societal Transitions 2, pp. 23-48.

Sijm, J. (2005). "The interaction between the EU emissions trading scheme and national energy policies". In: Climate Policy 5.1, pp. 79-96.

Trotignon, R. and A. Delbosc (2008). "Allowance trading patterns during the EU ETS trial period: What does the CITL reveal". In: Climate report 13.

Tuerk, A., M. Mehling, C. Flachsland, and W. Sterk (2009). "Linking carbon markets: concepts, case studies and pathways". In: Climate Policy 9.4, pp. 341-357.

Wei, X. (2015). "Three essays on carbon and environmental markets in the EU and China". In: unpublished PhD thesis, UNSW Business School, The University of New South Wales, Sydney, Australia.

Wei, X. and R. Betz (2016). "VAT Fraud in the Carbon Market: Empirical Evidence from the Phase II of the EU ETS". In: CEEM Working Paper (forthcoming).

World Bank (2014). State and trends of carbon pricing 2014. World Bank Publications. 


\section{A Appendix}

Registry codes correspond to: AT: Austria, AU: Australia, BE: Belgium, BG: Bulgaria, CDM: Clean Development Mechanism, CH: Switzerland, CY (CY0): Cyprus, CZ: Czech Republic, DE: Germany, DK: Denmark, EC: European Commission, EE: Estonia, ES: Spain, FI: Finland, FR: France, GB: United Kingdom, GR: Greece, HU: Hungary, IE: Ireland, IS: Iceland, IT: Italy, JP: Japan, LI: Liechtenstein, LT: Lithuania, LU: Luxembourg, LV: Latvia, MT (MT0): Malta, NL: Netherlands, NO: Norway, NZ: New Zealand, PL: Poland, PT: Portugal, RO: Romania, RU: Russian Federation, SE: Sweden, SI: Slovenia, SK: Slovakia, UA: Ukraine.

\section{A.1 Registries Time-Coverage}

Table 6: National Registries Time-Coverage in the Dataset. Registries joined the EU ETS program in different periods and sometimes the initial period of actual transactions involving a registry slightly differ in our data set between acquiring and transferring accounts. Registry codes refer to those reported in the EUTL system. Source: authors' own elaborations based on the EUTL transactions data set for the first two Phases.

\begin{tabular}{|c|c|c|}
\hline & Acquiring Register & Transferring Register \\
\hline AT & 2005-2012 & 2005-2012 \\
\hline AU & 2010-2012 & 2010-2012 \\
\hline BE & 2005-2012 & 2005-2012 \\
\hline BG & 2009-2012 & 2009-2012 \\
\hline CDM & - & 2008-2012 \\
\hline $\mathrm{CH}$ & 2008-2012 & 2008-2012 \\
\hline CY & 2010-2012 & 2010-2012 \\
\hline CYO & 2006-2008 & 2006-2008 \\
\hline CZ & 2005-2012 & 2005-2012 \\
\hline DE & 2005-2012 & 2005-2012 \\
\hline DK & 2005-2012 & 2005-2012 \\
\hline EC & 2008,2012 & 2008,2012 \\
\hline EE & 2005-2012 & 2005-2012 \\
\hline$\overline{\mathbf{E S}}$ & 2005-2012 & $2005-2012$ \\
\hline FI & 2005-2012 & 2005-2012 \\
\hline FR & 2005-2012 & 2005-2012 \\
\hline GB & 2005-2012 & 2005-2012 \\
\hline GR & 2006-2012 & 2006-2012 \\
\hline HU & 2006-2012 & 2006-2012 \\
\hline IE & 2005-2012 & 2005-2012 \\
\hline IS & 2012-2012 & 2012-2012 \\
\hline IT & 2006-2012 & 2006-2012 \\
\hline JP & 2008-2012 & 2008-2012 \\
\hline LI & 2008-2012 & 2008-2012 \\
\hline LT & 2005-2012 & 2005-2012 \\
\hline $\mathbf{L U}$ & 2006-2012 & 2006-2012 \\
\hline LV & 2005-2012 & 2005-2012 \\
\hline MT & 2009-2012 & 2009-2012 \\
\hline MT0 & 2007-2008 & 2007-2008 \\
\hline NL & 2005-2012 & 2005-2012 \\
\hline NO & $2008-2012$ & 2009-2012 \\
\hline NZ & 2009-2012 & 2008-2012 \\
\hline PL & 2006-2012 & 2006-2012 \\
\hline $\mathbf{P T}$ & 2005-2012 & 2005-2012 \\
\hline RO & $2008-2012$ & $2008-2012$ \\
\hline RU & & 2011-2012 \\
\hline SE & 2005-2012 & 2005-2012 \\
\hline SI & 2005-2012 & 2005-2012 \\
\hline SK & 2005-2012 & 2005-2012 \\
\hline UA & - & 2009-2012 \\
\hline
\end{tabular}

\section{A.2 Focus on Account Types}

This Appendix presents a detailed analysis on account types corresponding to Pending Accounts (PAs), Cancellation Accounts (CAs), Voluntary Cancellation Accounts (VCAs), Retirement Accounts (RAs), Holding Accounts (HAs) and those indicates as Not Available Accounts (NAs).

As regards PAs, they are involved in CDM transactions. Out of the 5964 transactions with transferring registry corresponding to CDM the largest share (5765) involve PAs while the remaining 199 refer to HAs. PAs total transferred amount is modest $(522,592,487$ units, which correspond to the 0.34 per cent of the overall volume).

CAs and VCAs are national registry accounts through which allowances are definitively cancelled without accounting them against verified emissions, while RAs refer to the retirement of units by the (Party) Retirement Account for that period and their accounting in accordance with Kyoto Protocol obligations. As shown in Table 2, CAs and VCAs are involved in less than 0.1 per cent of the transferred units. Conversely, those few transactions involving RAs represent the 8.34 per cent of the overall volume.

The data set provided by EUTL reports a consistent percentage of transactions involving accounts with type code equal to 100 (Holding Accounts). This category was enlarged after the switch over in June 2012 
from the Member States' national registries to a single Union Registry, which provided a harmonized basis to transfer allowances across the EU. The Union Registry is divided into two sections: the EU section and the Kyoto section. In the EU section the account type code 100 includes Aircraft Operator Holding Accounts $^{37}$ (hereinafter, AOHAs), Operator Holding Accounts, Person Holding Accounts, and Trading Accounts (hereinafter, TAs) which are managed by Member States of the EU ETS. Instead, in the Kyoto section are recorded with code 100 the former Operator Holding Accounts and the Person Holding Accounts that existed in the national registries prior to the switch-over to the Union registry.

Hence, in the EUTL data set OHAs with account type code 100 coexist with (Former) OHAs with account type code 120, and PHAs with account type code 100 coexist with (Former) PHAs with account type code 121. The main difference is that the new OHAs and PHAs can hold EU allowances and Kyoto units eligible for use in the EU ETS (such as CER and ERU), while (Former) OHAs and PHAs in national registry can hold Kyoto units but not EU allowances ${ }^{38}$.

There are 4602 HAs for which the name of the account identifier is available. They represent about 91 per cent and 96 per cent of the transactions involving HAs as transferring or acquiring counterparts, respectively. The inspection of the details of such transactions reveals that HAs are related to 3502 account holders. To disentangle the constituents of the latter group we exploit an additional data set provided by EUTL $^{39}$. Using the account holder names we are able to map a subset of 3476 HAs to the EUTL accounts data set ${ }^{40}$. A portion of HAs refer to: (i) new participants (new OHAs and PHAs, but also the novel types AOHAs and TAs) registered after the deployment of the Union registry in mid-2012; (ii) OHAs and PHAs that closed an old account in their national registers and opened a new one in the EU section of the Union registry; (iii) PHAs that opted for more flexible accounts, the TAs. Trading Accounts are in fact comparable to PHAs, but are designed for account holders who trade frequently ${ }^{41}$. The remaining HAs refer to (Party) Holding Accounts through which allowances are for instance allocated and surrendered and to a bundle of other government or EU Commission accounts used to manage administrative transfers. These accounts refer to only about 50 account holders, however they are responsible for more than 90 per cent of the transferred amount referred to HAs either as transferring or acquiring counterparts. Therefore, despite the large number of different account types classified as HAs since the introduction of the Union Registry in mid-2012, the latter group is mainly driven by Party accounts. In any case, the changes introduced by the Union Registry have a limited impact on our sample as they concern only the last few months of 2012.

Finally, following a similar procedure to the one described above for HAs, we investigated NAs in Table 2. Exploiting the EUTL details of the transactions, it turns out that missing values are spread across all registries in the EU ETS. For these transfers not only the transferring/acquiring type is not directly available, but also the identity of the counterparts is often present only in the details of the transaction. The complete mapping with the other EUTL data set, therefore, turns out to be very burdensome especially for acquiring NAs, that represent about one-sixth of the total number of transactions. We are able to map the account identity information from the details of the transactions to the EUTL accounts data set for a consistent portion of transferring and acquiring NAs. The exploitation of the matched information reveals that this set of records includes installation and person accounts, but also Party accounts. In some cases, however, even the details of the transactions do not show the name of the counterpart, thus preventing a complete matching. This hinders the possibility to allocate NAs to the underlying account types. We decided, therefore, to consider the set of transactions involving NAs a separate block from the others due to incomplete matching.

\section{A.3 Main Accounts Participants}

In this Appendix we report an example of some main accounts for both OHA and PHA in terms of transferred amount during the entire reference period. We distinguish among transferring and acquiring counterparts.

\footnotetext{
${ }^{37}$ The aviation sector was covered by the EU ETS since January 2012, although the application for flights to and from nonEuropean countries was suspended for year 2012.

${ }^{38} \mathrm{EU}$ allowances (EUAs) are the allowances for the stationary operators within the EU ETS. AAUs are Assigned Amount Units which refer to certificates under the Kyoto Protocol. Parties listed in Annex B of the Kyoto Protocol can trade in AAUs and use them to fulfil their obligations according to Article 3 (1) of the Kyoto Protocol. Trading in International credits has been available since Phase II (Linking Directive 2004/101/EC). Certified Emission Reduction units (CERs) are issued by the CDM registry for emission reduction in $\mathrm{CDM}$ projects that reduce emissions in developing countries, while Emission Reduction Units from AAU (ERUs) are issued for Joint Implementation projects that reduce emissions in industrialized countries. Each Member State of the EU ETS is required to publish the International Credit Entitlement (ICE) for each of its operators according to Article 2.1 of the External RICE Regulation. In Phase II accounts used 1.058 billion tonnes of international credits. For detail see e.g. DEHSt (2015) and EC (2015).

${ }^{39}$ We extract information from the Accounts table available from: http://ec.europa.eu/environment/ets/account.do. As noted in Liu et al. (2017), if data sets are retrieved at different times some accounts may have changed their profile information. The EUTL transactions data set has now a three-year period of embargo according to the Annex XIV (4) of Regulation 389/2013, while the information on the accounts profiles are updated regularly. This may introduce some discrepancies in the mapping due to accounts changing their profiles over time. In our study, EUTL data sets are retrieved in May 2017.

${ }^{40} \mathrm{~A}$ similar mapping is obtained using the account identifier name instead of the account holder name as the main key for matching information across EUTL data sets; the corresponding results are available from the authors upon request.

41 TAs represent very active accounts. Differently from other HAs, TAs are allowed to transfers to accounts included in their Trusted Account List (TAL) without being subject to the requirement of 26 hours transaction delay. Alternatively, they can make transfers involving counterparts outside their TALs provided they respect the transaction delay requirement.
} 
Table 7: Top participants. We report the first 20 participants in terms of transferred amount during the period 2005-2012. We consider OHAs and PHAs and transactions types 3-0,3-21 and 10-0. For both account types we show the rank in terms of both transferring and acquiring accounts identifiers. Source: authors' own elaborations based on the EUTL transactions data set for the first two Phases.

\section{OHA (code 120) Acquiring}

Operator Account

\begin{tabular}{l|c|} 
Operator Account & 343044921 \\
\hline 1474 - Anlagenkonto & 61023956 \\
\hline PGE Górnictwo i Energetyka Konwencjonalna S.A. & 49242562 \\
\hline 1667 - Anlagenkonto & 49104071 \\
\hline Ratcliffe on Soar Power Station & 45091505 \\
\hline 1624 - Anlagenkonto & 42426614 \\
\hline 1625 - Anlagenkonto & 40273170 \\
\hline 71 - Anlagenkonto & 38373136 \\
\hline Hidrocantábrico S.A - Aboño 1 & 37048650 \\
\hline 074 Electrabel - Centrale Rodenhuize & 32947856 \\
\hline 1623 - Anlagenkonto & 32465102 \\
\hline Endesa Generación - Teruel & 31665599 \\
\hline Endesa Generación, S.A. - Puentes & 30159384 \\
\hline ArcelorMittal Atlantique Lorraine - Dunkerque & 29176817 \\
\hline 87 - Anlagenkonto & 27972385 \\
\hline 2026 - Anlagenkonto & 27953828 \\
\hline Heizkraftwerk Heilbronn & 24555989 \\
\hline ELEKTROWNIA & 22911168 \\
\hline Eggborough Operator Account & 22684708 \\
\hline Endesa Generación, S.A. - Compostilla & 22213320 \\
\hline
\end{tabular}

PHA (code 121) Acquiring

\# Units

BlueNext Détention

BARCLAYS

CONSUS FR PWX

Barclays Capital B

Endesa Generación, S.A

BlueNext SA

RWE Supply \& Trading GmbH

ARCELOR TREASURY Détention

STX SERVICES B.V. Détention

1914 - RWE Power AG Personenkonto

STX Serrvices

BNP Paribas Détention

VertisHU Trading:DK400

BNP Paribas Commodity Futures Limited

Climate Corporation PWX

1899 - Vattenfall Energy Trading GmbH

ICE Clear Trading

Deutsche Bank AG, London Branch

2160 - KfW Personenkonto

1903 - BHF - Bank Aktiengesellschaft Personenkonto
| $1808087129 \mid$

| 739436581

455069791

$422957441 \mid$

| 307438782

| 304897578

292871123

| 277327923

| 268559589

| 261045813

| 249065470

| 238960242

| 229328238 |

| 229305579

| 223846563

$\mid 200352701$

199936271

185957257

| 175648000

172727354

\section{OHA (code 120) Transferring}

\section{\# Units}

Operator Account

87 - Anlagenkonto

605977180

71 - Anlagenkonto

72857355

\begin{tabular}{l|l|}
\hline Scunthorpe Integrated Steel Works & 65577904 \\
\hline
\end{tabular}

\begin{tabular}{l|l}
\hline ARCELORMITTAL ESPAÑA, S.A. & 54598693 \\
\hline
\end{tabular}

\begin{tabular}{l|l|}
\hline ArcelorMittal Atlantique Lorraine - Dunkerque & 47711988 \\
\hline
\end{tabular}

\begin{tabular}{l|c|}
\hline 011 ArcelorMittal Gent & 47566931 \\
\hline
\end{tabular}

\begin{tabular}{|l|c|}
\hline Essent Amercentrale & 45868191 \\
\hline
\end{tabular}

\begin{tabular}{l|l|}
\hline PGE Górnictwo i Energetyka Konwencjonalna S.A. & 45596071 \\
\hline
\end{tabular}

\begin{tabular}{l|l|}
\hline Ratcliffe on Soar Power Station & 45025576 \\
\hline
\end{tabular}

\begin{tabular}{l|l|}
\hline Eggborough Operator Account & 37528238 \\
\hline
\end{tabular}

\begin{tabular}{|l|l|}
\hline Statoil ASA Bragefeltet & 37032372 \\
\hline
\end{tabular}

\begin{tabular}{|l|l|}
\hline Tata Steel IJmuiden bv & 36521611 \\
\hline
\end{tabular}

\begin{tabular}{|l|l|}
\hline 61 - Anlagenkonto & 32298229 \\
\hline
\end{tabular}

\begin{tabular}{l|l|}
\hline ELEKTROWNIA & 31518470 \\
\hline
\end{tabular}

\begin{tabular}{l|l|}
\hline ARCELORMITTAL MEDITERRANEE & 30702117 \\
\hline
\end{tabular}

\begin{tabular}{|l|l|}
\hline Endesa Generación - Teruel & 30602984 \\
\hline
\end{tabular}

\begin{tabular}{l|l}
\hline ENGIE Energie Nederland N.V. Centrale Gelderland & 30551649
\end{tabular}

\begin{tabular}{l|c|}
\hline 78 - Anlagenkonto & 28186064 \\
\hline
\end{tabular}

\begin{tabular}{l|r|}
\hline Endesa Generación, S.A. - Puentes & 23565668 \\
\hline
\end{tabular}

PHA (code 121) Transferring \# Units

BlueNext Détention

| 1808087129

\begin{tabular}{|l|l|}
\hline ICE Clear Trading & 1117433585 \\
\hline
\end{tabular}

\begin{tabular}{|l|r|}
\hline BARCLAYS & 719999412
\end{tabular}

\begin{tabular}{|l|l|}
\hline Barclays Capital B & 636476573 \\
\hline
\end{tabular}

\begin{tabular}{|l|l|}
\hline CONSUS FR PWX & 455068903 \\
\hline
\end{tabular}

\begin{tabular}{l|l}
\hline BNP Paribas Commodity Futures Limited & 453098838
\end{tabular}

\begin{tabular}{|l|l|}
\hline Deutsche Bank AG, London Branch & 384906465 \\
\hline
\end{tabular}

\begin{tabular}{|l|c|}
\hline BlueNext SA & 304897578 \\
\hline
\end{tabular}

\begin{tabular}{l|c}
\hline Newedge Group (UK Branch) & 303184080
\end{tabular}

\begin{tabular}{|l|l|}
\hline RWE Supply \& Trading GmbH & 284568682 \\
\hline
\end{tabular}

\begin{tabular}{|l|l|}
\hline Endesa Generación, S.A. & 270409344 \\
\hline
\end{tabular}

\begin{tabular}{|l|l|}
\hline STX SERVICES B.V. Détention & 268100598 \\
\hline
\end{tabular}

\begin{tabular}{l|l}
\hline 1914 - RWE Power AG Personenkonto & 260276894 \\
\hline
\end{tabular}

\begin{tabular}{l|l}
\hline STX Serrvices & 249065470
\end{tabular}

\begin{tabular}{|l|r|}
\hline BNP Paribas Détention & 235277343 \\
\hline
\end{tabular}

\begin{tabular}{l|l|}
\hline VertisHU Trading:DK400 & 227119679
\end{tabular}

\begin{tabular}{l|l}
\hline Climate Corporation PWX & 223127613
\end{tabular}

\begin{tabular}{l|l|}
\hline Citigroup Global Markets Limited & 213163383 \\
\hline
\end{tabular}

\begin{tabular}{|l|l|}
\hline UBS Limited Trading & 200559000 \\
\hline
\end{tabular}

\begin{tabular}{|l|l|}
\hline 1899 - Vattenfall Energy Trading GmbH & 185994758 \\
\hline
\end{tabular} 


\section{A.4 Time series flows of OHAs and PHAs}

Figure 8: Time series of flows (in million of units) from and to OHAs and PHAs under the core specification (transaction types: 3-0, 3-21, and 10-0). We denote with $\_A$ or $\_T$ if the curve refers to acquiring or transferring accounts, respectively. For instance $O H A s_{-} A$ means that we filter the accounts which are $\mathrm{OHAs}$ as acquiring counterparts. We also limit the second counterpart to account types different from the first type. For instance $O H A s_{-} A\left(n o O H A s_{-} T\right)$ means that we are considering OHAs as acquiring counterparts and we exclude OHAs as their respective transferring counterparts. Source: authors' own elaborations based on the EUTL transactions data set for the first two Phases.

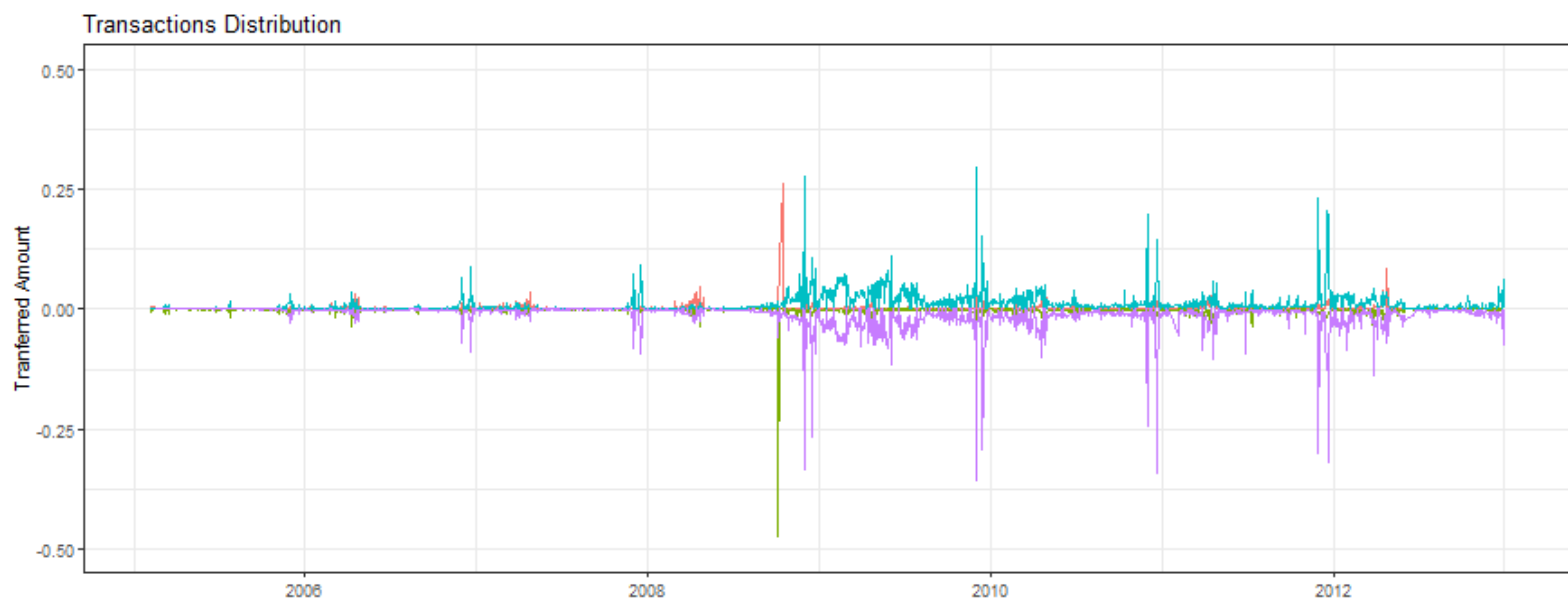

Transactions Distribution
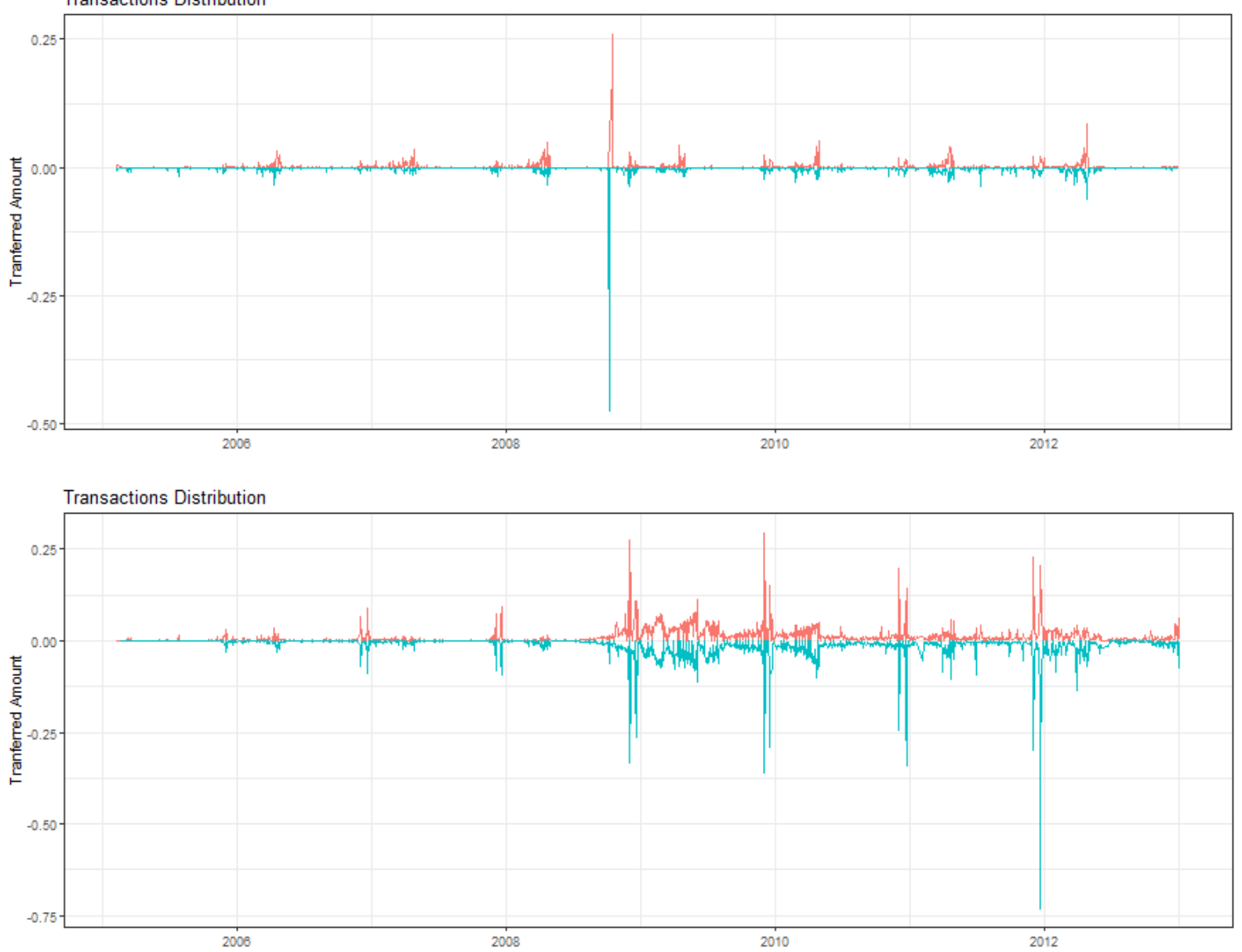


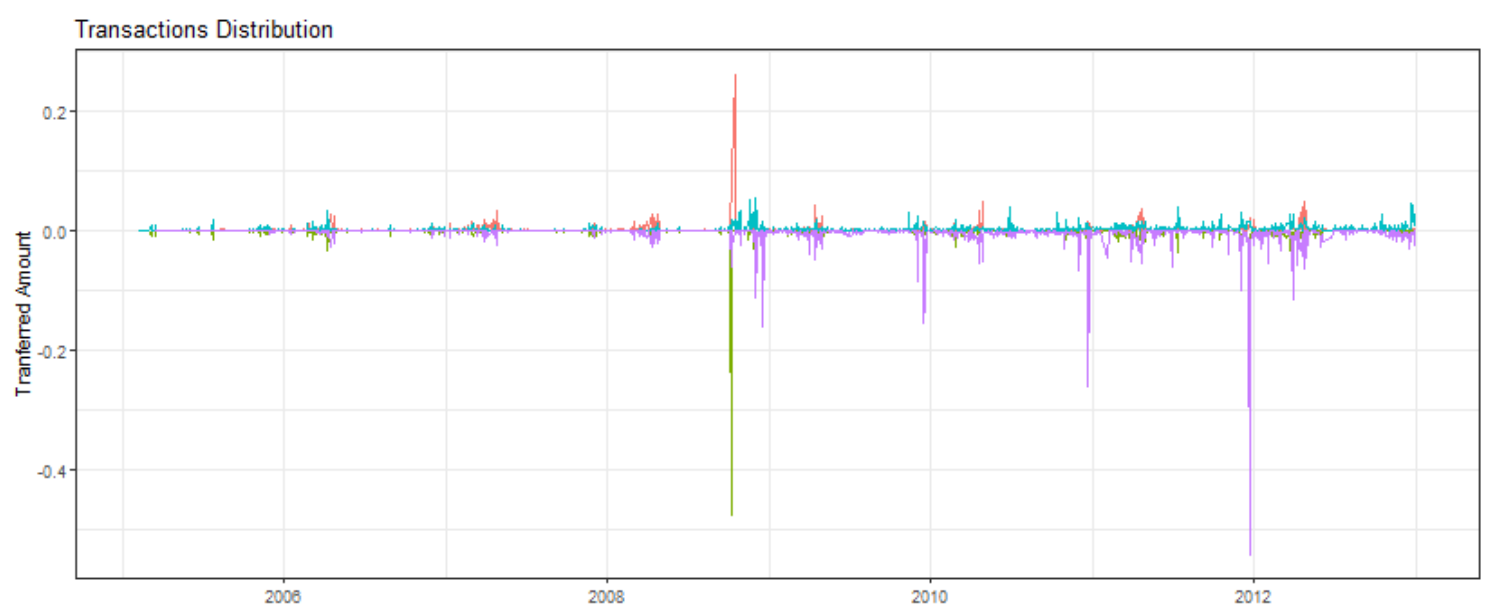

- OHAs_A (no OHA_T)
- OHAs_T (no OHA_A $)$
- PHAs_A (no PHA_T $)$
- PHAs_T (no PHA_A $)$

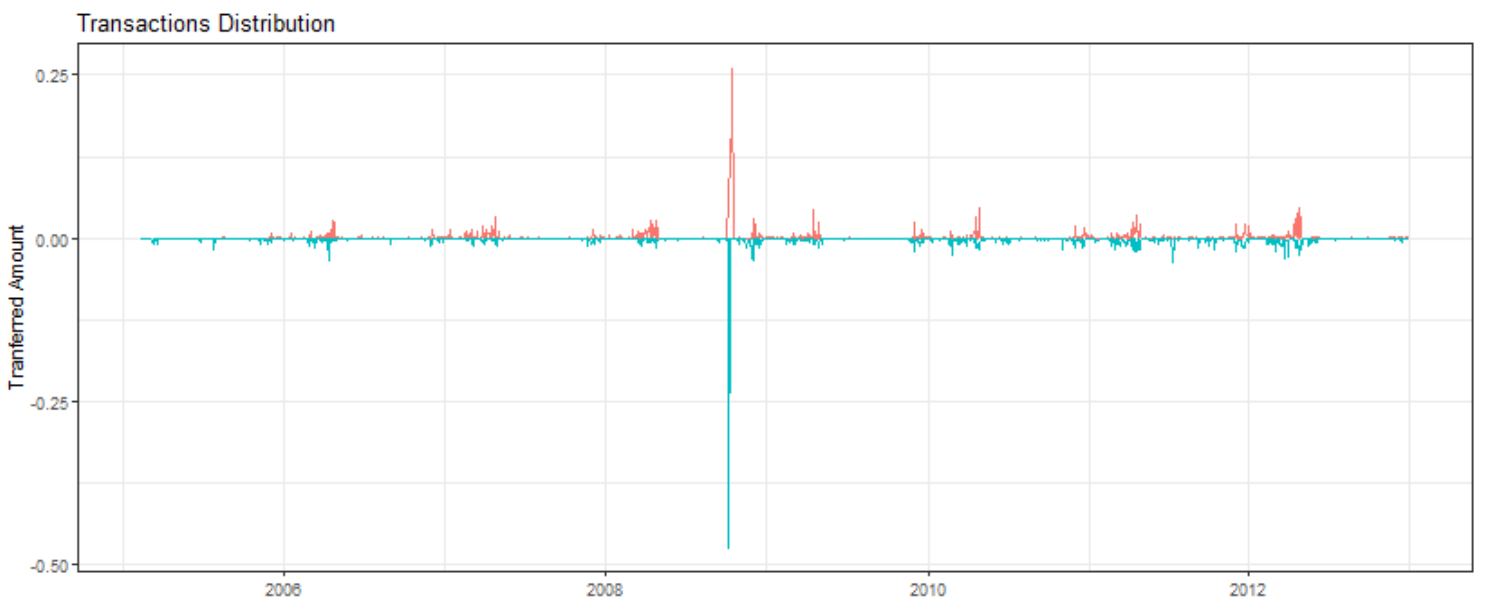

- OHAs_A (no OHA

- OHAs_T (nO OHA_A)

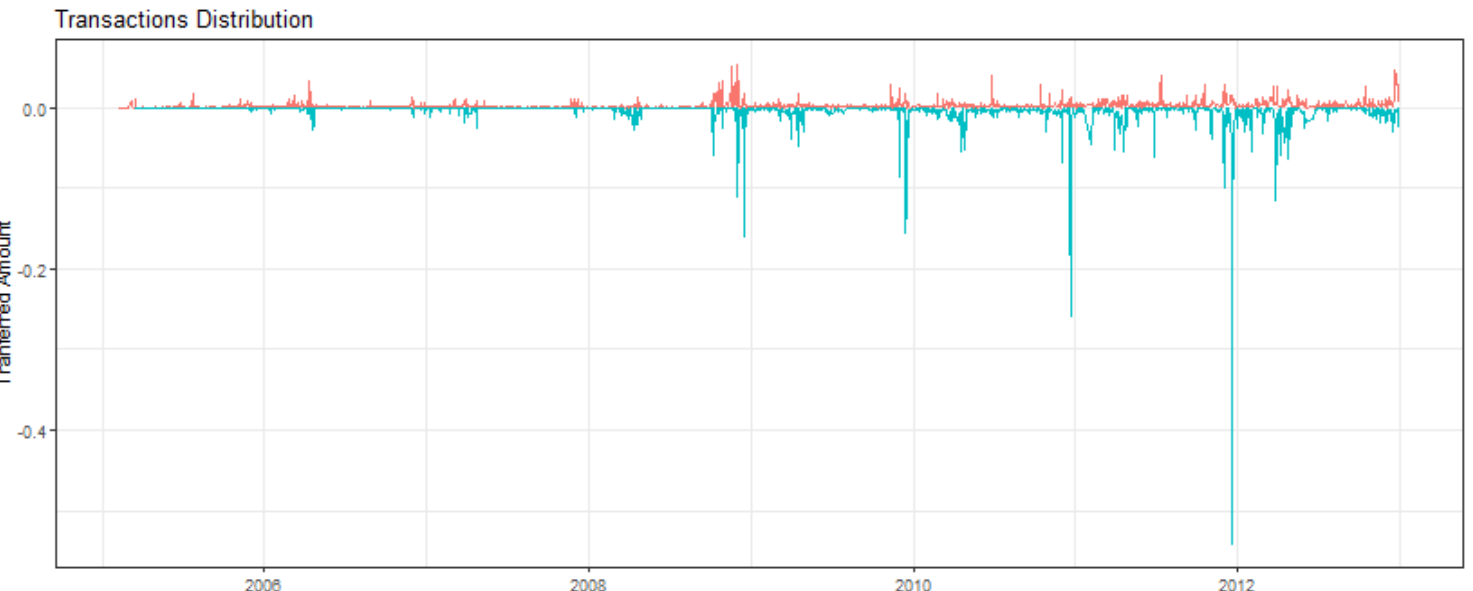

- PHAs_A (no PHA_T

- PHAs_T (no PHA_A) 


\section{A.5 Centrality Scores: Pageranks in scenario $b$ (transactions types: $3-0$, $3-21,10-0,10-2,10-52,10-53$, and 10-61)}

Table 8: Network Statistics: PageRanks. For each registry we show different specifications according to specific subsets of account types: OHA, PHA, OHA \& PHA, OHA \& PHA \& HA, and all types of accounts, respectively. We report the mean values (mean) of the period and the standard deviation (sd). Values are shown separately for Phase I and Phase II of the EU ETS program and for the overall sample period (in bold). Source: authors' own elaborations based on the EUTL transactions data set for the first two Phases.

\begin{tabular}{|c|c|c|c|}
\hline & & & \\
\hline & mean & sd & mean \\
\hline Austria (AT) & 0,04 & $5,61 \%$ & 0,04 \\
\hline Phase I & 0,01 & $1,28 \%$ & 0,06 \\
\hline Phase II & 0,06 & $8,00 \%$ & 0,04 \\
\hline Belgium (BE) & 0,04 & $5,68 \%$ & 0,02 \\
\hline Phase I & 0,04 & $6,61 \%$ & 0,01 \\
\hline Phase II & 0,05 & $5,17 \%$ & 0,03 \\
\hline Bulgaria & 0,00 & $0,39 \%$ & 0,01 \\
\hline Phase II & 0,00 & $0,39 \%$ & 0,01 \\
\hline Cyprus (CY) & 0,00 & $0,78 \%$ & 0,00 \\
\hline Phase I & 0,00 & $0,00 \%$ & 0,00 \\
\hline Phase II & 0,00 & $1,21 \%$ & 0,00 \\
\hline Czech Republic (CZ) & 0,06 & $9,42 \%$ & 0,05 \\
\hline Phase I & 0,03 & $5,03 \%$ & 0,05 \\
\hline Phase II & 0,08 & $11,84 \%$ & 0,05 \\
\hline Denmark (DK) & 0,06 & $7,30 \%$ & 0,10 \\
\hline Phase I & 0,06 & $7,46 \%$ & 0,15 \\
\hline Phase II & 0,06 & $7,22 \%$ & 0,07 \\
\hline Estonia $(\boldsymbol{E E})$ & 0,01 & $2,40 \%$ & 0,01 \\
\hline Phase I & 0,02 & $2,85 \%$ & 0,00 \\
\hline Phase II & 0,01 & $2,16 \%$ & 0,01 \\
\hline European Commission (EC) & 0,00 & $0,00 \%$ & 0,00 \\
\hline Phase II & 0,00 & $0,00 \%$ & 0,00 \\
\hline Finland $(F I)$ & 0,07 & $8,91 \%$ & 0,04 \\
\hline Phase I & 0,07 & $9,94 \%$ & 0,05 \\
\hline Phase II & 0,06 & $8,35 \%$ & 0,04 \\
\hline France $(F R)$ & 0,07 & $10,81 \%$ & 0,10 \\
\hline Phase I & 0,04 & $4,48 \%$ & 0,11 \\
\hline Phase II & 0,09 & $14,28 \%$ & 0,09 \\
\hline Germany (DE) & 0,13 & $13,07 \%$ & 0,10 \\
\hline Phase I & 0,22 & $19,68 \%$ & 0,12 \\
\hline Phase II & 0,09 & $9,44 \%$ & 0,08 \\
\hline Greece (GR) & 0,01 & $2,45 \%$ & 0,01 \\
\hline Phase I & 0,00 & $0,42 \%$ & 0,00 \\
\hline Phase II & 0,02 & $3,57 \%$ & 0,01 \\
\hline Hungary $(H U)$ & 0,05 & $6,45 \%$ & 0,01 \\
\hline Phase I & 0,06 & $6,36 \%$ & 0,00 \\
\hline Phase II & 0,04 & $6,50 \%$ & 0,01 \\
\hline Iceland (IS) & 0,00 & $0,00 \%$ & 0,00 \\
\hline Phase II & 0,00 & $0,00 \%$ & 0,00 \\
\hline Ireland (IR) & 0,01 & $1,90 \%$ & 0,02 \\
\hline Phase I & 0,01 & $2,31 \%$ & 0,01 \\
\hline Phase II & 0,01 & $1,68 \%$ & 0,02 \\
\hline Italy (IT) & 0,06 & $10,04 \%$ & 0,04 \\
\hline Phase I & 0,07 & $8,43 \%$ & 0,03 \\
\hline Phase II & 0,05 & $10,92 \%$ & 0,05 \\
\hline Latvia $(L V)$ & 0,01 & $2,59 \%$ & 0,00 \\
\hline Phase I & 0,02 & $3,21 \%$ & 0,00 \\
\hline Phase II & 0,01 & $2,25 \%$ & 0,00 \\
\hline Liechtenstein (LI) & 0,00 & $0,00 \%$ & 0,01 \\
\hline Phase II & 0,00 & $0,00 \%$ & 0,01 \\
\hline Lithuania (LT) & 0,01 & $2,43 \%$ & 0,01 \\
\hline Phase I & 0,01 & $2,47 \%$ & 0,01 \\
\hline Phase II & 0,01 & $2,41 \%$ & 0,01 \\
\hline Luxembourg ( $L U)$ & 0,00 & $0,65 \%$ & 0,01 \\
\hline Phase I & 0,00 & $0,27 \%$ & 0,00 \\
\hline Phase II & 0,00 & $0,86 \%$ & 0,01 \\
\hline Malta $(M T)$ & 0,00 & $2,26 \%$ & 0,00 \\
\hline Phase I & 0,00 & $1,17 \%$ & 0,00 \\
\hline Phase II & 0,00 & $2,86 \%$ & 0,00 \\
\hline Netherlands (NL) & 0,04 & $6,01 \%$ & 0,09 \\
\hline Phase I & 0,06 & $6,32 \%$ & 0,11 \\
\hline Phase II & 0,03 & $5,83 \%$ & 0,08 \\
\hline Norway (NO) & 0,01 & $1,68 \%$ & 0,01 \\
\hline Phase II & 0,01 & $1,68 \%$ & 0,01 \\
\hline Others & 0,00 & $0,00 \%$ & 0,00 \\
\hline Phase II & 0,00 & $0,00 \%$ & 0,00 \\
\hline Poland (PL) & 0,04 & $4,70 \%$ & 0,04 \\
\hline Phase I & 0,02 & $3,16 \%$ & 0,02 \\
\hline Phase II & 0,05 & $5,55 \%$ & 0,05 \\
\hline Portugal (PT) & 0,04 & $6,16 \%$ & 0,02 \\
\hline Phase I & 0,03 & $3,36 \%$ & 0,01 \\
\hline Phase II & 0,05 & $7,69 \%$ & 0,03 \\
\hline Romania (RO) & 0,00 & $1,32 \%$ & 0,01 \\
\hline Phase II & 0,00 & $1,32 \%$ & 0,01 \\
\hline Slovakia (SK) & 0,02 & $3,34 \%$ & 0,02 \\
\hline Phase I & 0,01 & $1,70 \%$ & 0,01 \\
\hline Phase II & 0,03 & $4,25 \%$ & 0,03 \\
\hline Slovenia (SI) & 0,01 & $2,15 \%$ & 0,01 \\
\hline Phase I & 0,01 & $2,93 \%$ & 0,01 \\
\hline Phase II & 0,01 & $1,72 \%$ & 0,01 \\
\hline Spain $(E S)$ & 0,07 & $8,24 \%$ & 0,07 \\
\hline Phase I & 0,04 & $6,64 \%$ & 0,07 \\
\hline Phase II & 0,09 & $9,13 \%$ & 0,07 \\
\hline Sweden (SE) & 0,03 & $3,92 \%$ & 0,04 \\
\hline Phase I & 0,07 & $7,44 \%$ & 0,04 \\
\hline Phase II & 0,01 & $1,99 \%$ & 0,04 \\
\hline Switzerland (CH) & 0,00 & $0,00 \%$ & 0,00 \\
\hline Phase II & 0,00 & $0,00 \%$ & 0,00 \\
\hline Ukraine (UA) & 0,00 & $0,00 \%$ & 0,00 \\
\hline Phase II & 0,00 & $0,00 \%$ & 0,00 \\
\hline United Kingdom (GB) & 0,07 & $8,34 \%$ & 0,12 \\
\hline $\begin{array}{l}\text { Phase I } \\
\text { P }\end{array}$ & 0,10 & $9,77 \%$ & 0,12 \\
\hline Phase II & 0,05 & $7,55 \%$ & 0,11 \\
\hline
\end{tabular}


A.6 PageRank under scenario $b$ (transactions types: 3-0, 3-21, 10-0, 10-2, 10-52, 10-53, and 10-61)

Figure 9: PageRanks for different Account Types and Transaction Codes (Scenario b). We consider only the most central registries: Denmark (DK), France (FR), Germany (DE), Great Britain (GB) and the Netherlands (NL). We present four cases: OHAs, PHAs, OHAs \& PHAs, and all the account types specification. Source: authors' own elaborations based on the EUTL transactions data set for the first two Phases.
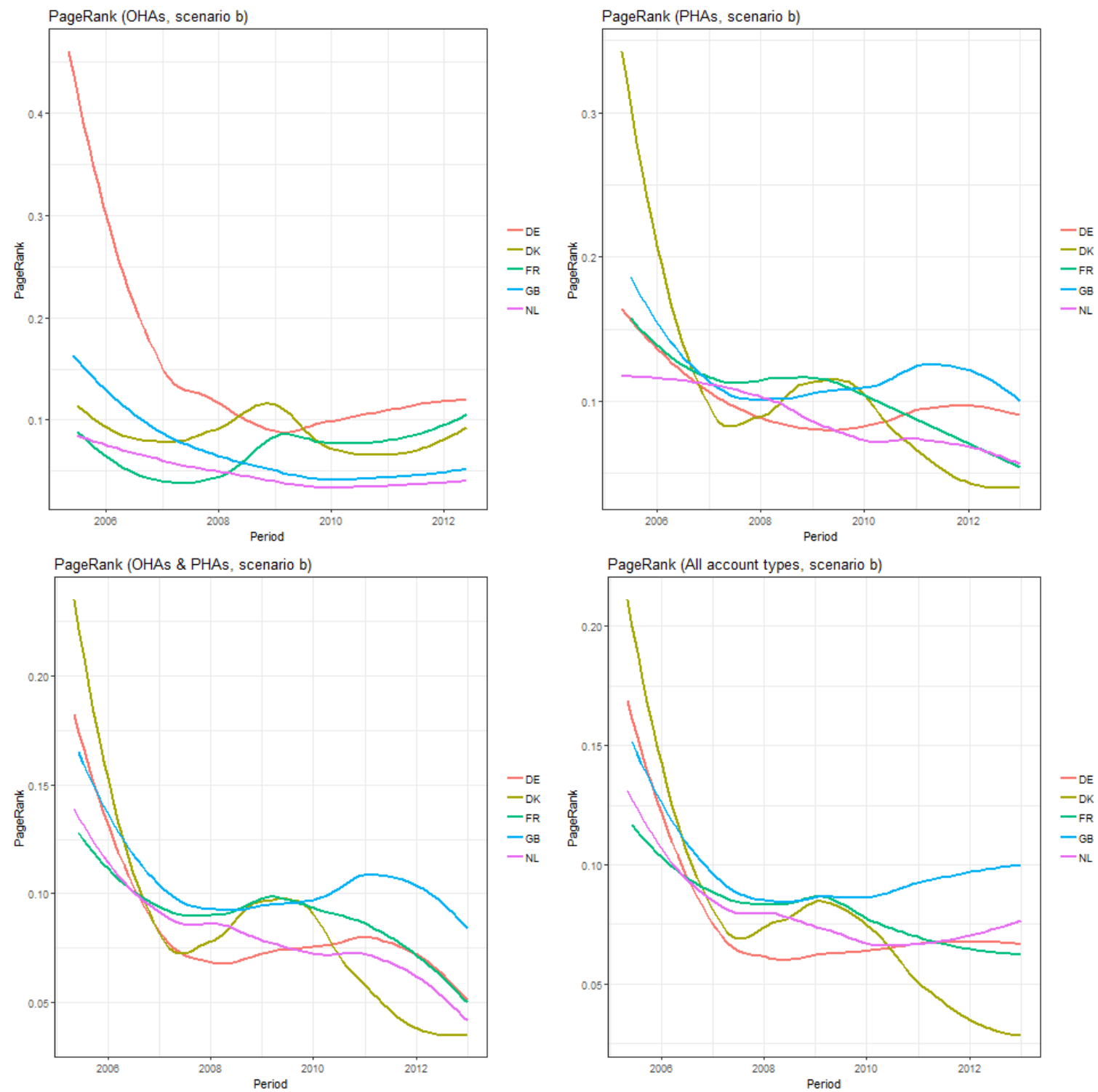
A.7 Assortativity coefficients under the core scenario (transactions types: 3-0, 3-21, 10-0)

Figure 10: Assortativity Coefficients (IN-OUT and OUT-IN) for OHAs, PHAs, OHAs \& PHAs, and all types of account under the core scenario. Source: authors' own elaborations based on the EUTL transactions data set for the first two Phases.
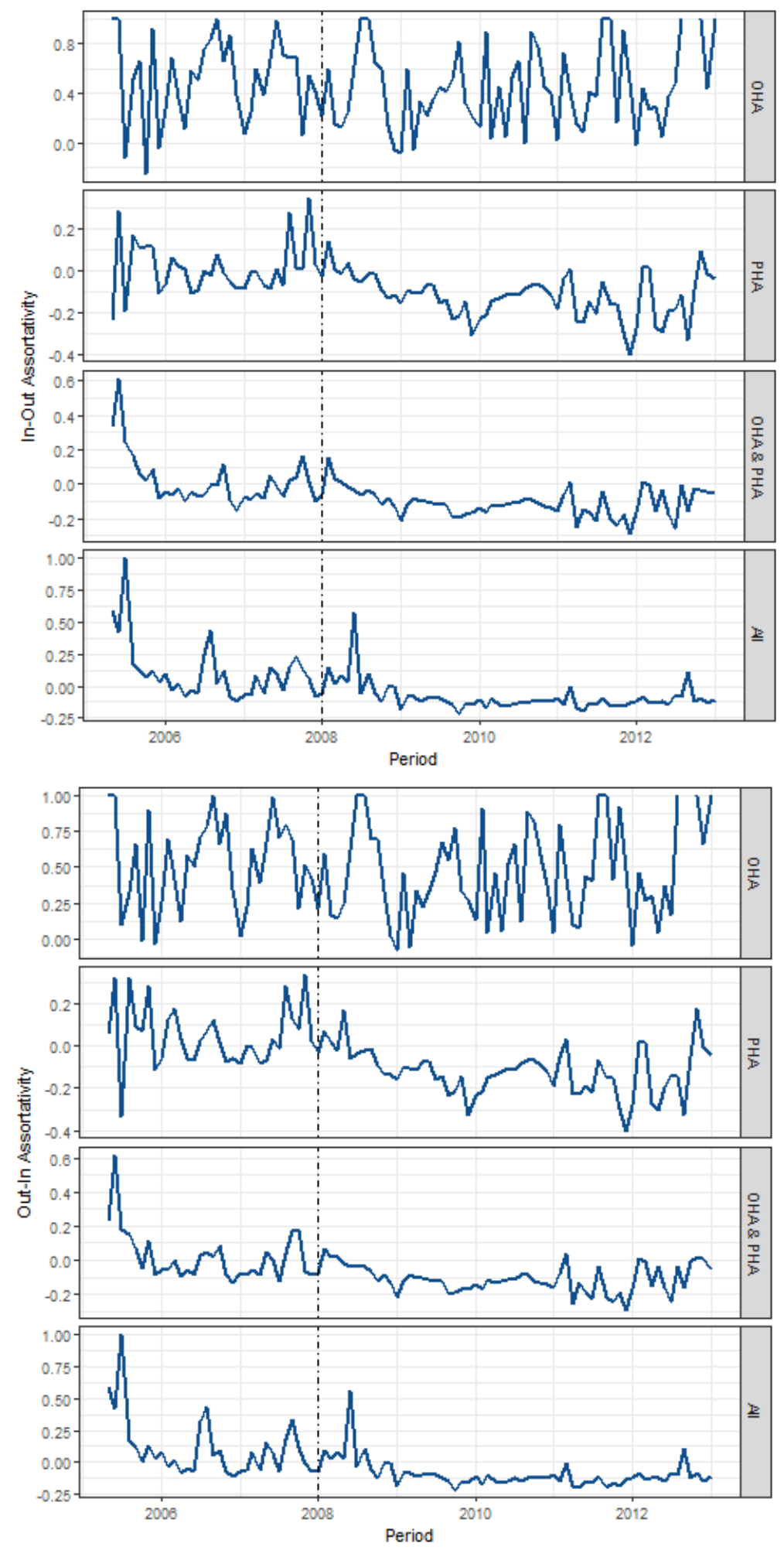
A.8 Assortativity coefficients under scenario $b$ (transactions types: $3-0$, $3-21,10-0,10-2,10-52,10-53$, and 10-61)

Figure 11: Assortativity Coefficients (IN-IN and OUT-OUT) for OHAs, PHAs, OHAs \& PHAs, and all types of account under scenario b. Source: authors' own elaborations based on the EUTL transactions data set for the first two Phases.
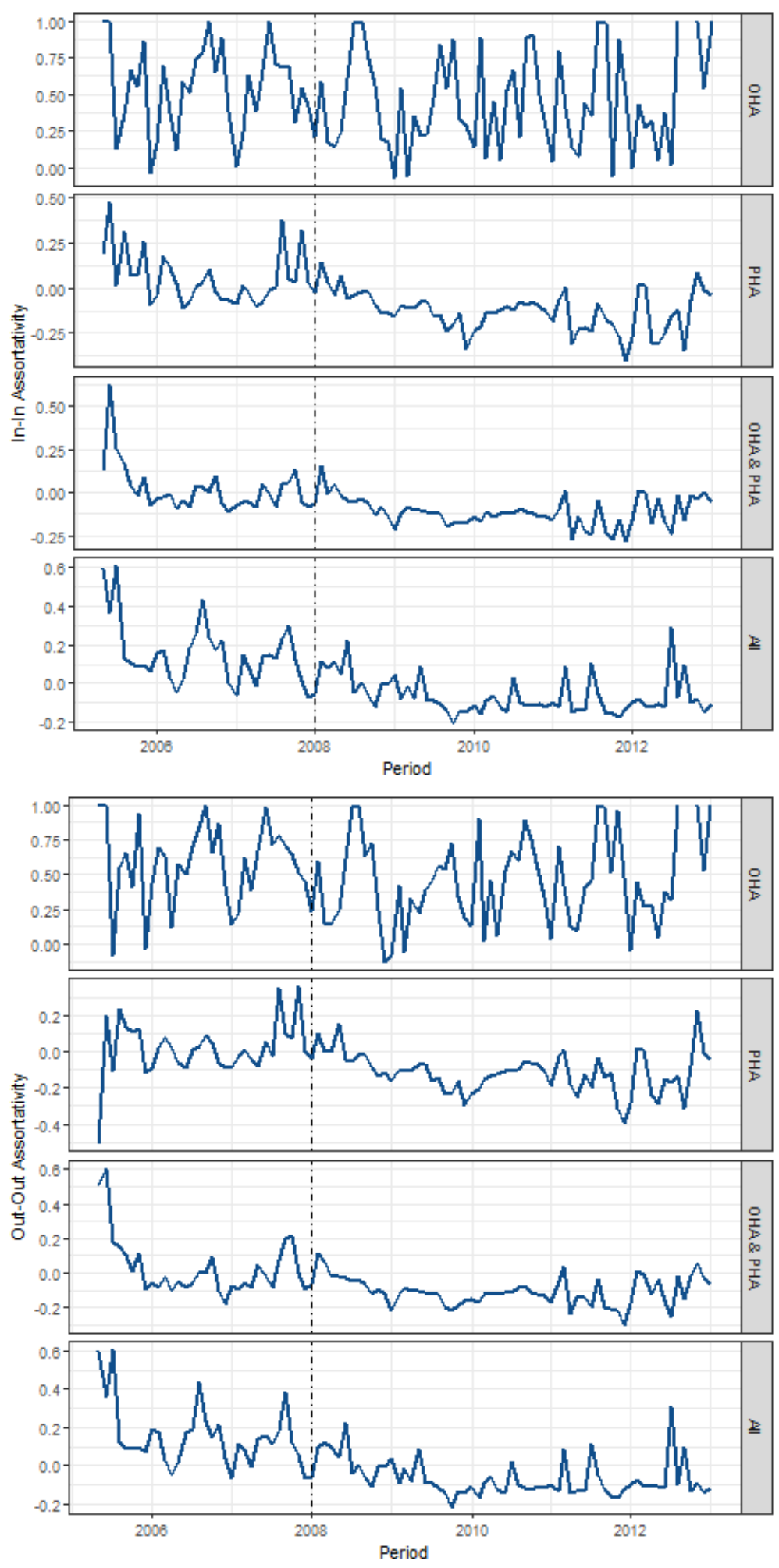
Figure 12: Assortativity Coefficients (IN-OUT and OUT-IN) for OHAs, PHAs, OHAs \& PHAs, and all types of account under scenario $b$. Source: authors' own elaborations based on the EUTL transactions data set for the first two Phases.
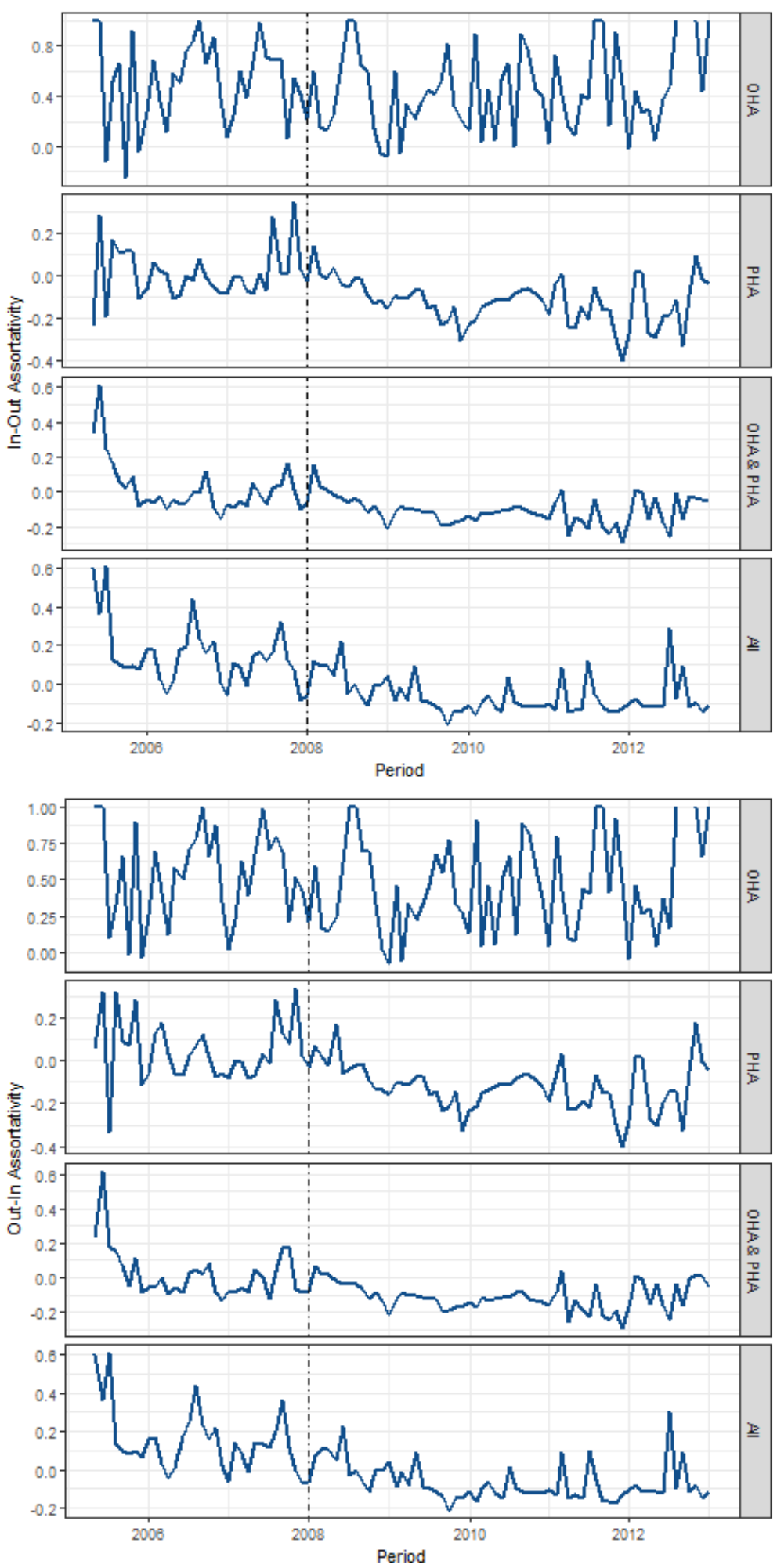


\section{A.9 Country-level Centrality Scores: PageRanks in the core scenario (transactions types: $3-0,3-21$, and 10-0)}

Table 9: Network Statistics: PageRanks. For each registry we show different specifications according to specific subsets of account types: OHA, PHA, OHA \& PHA, OHA \& PHA \& HA, and all types of accounts, respectively. We report the mean values (mean) of the period and the standard deviation (sd). Values are shown separately for Phase I and Phase II of the EU ETS program and for the overall sample period (in bold). Source: authors' own elaborations based on the EUTL transactions data set for the first two Phases.

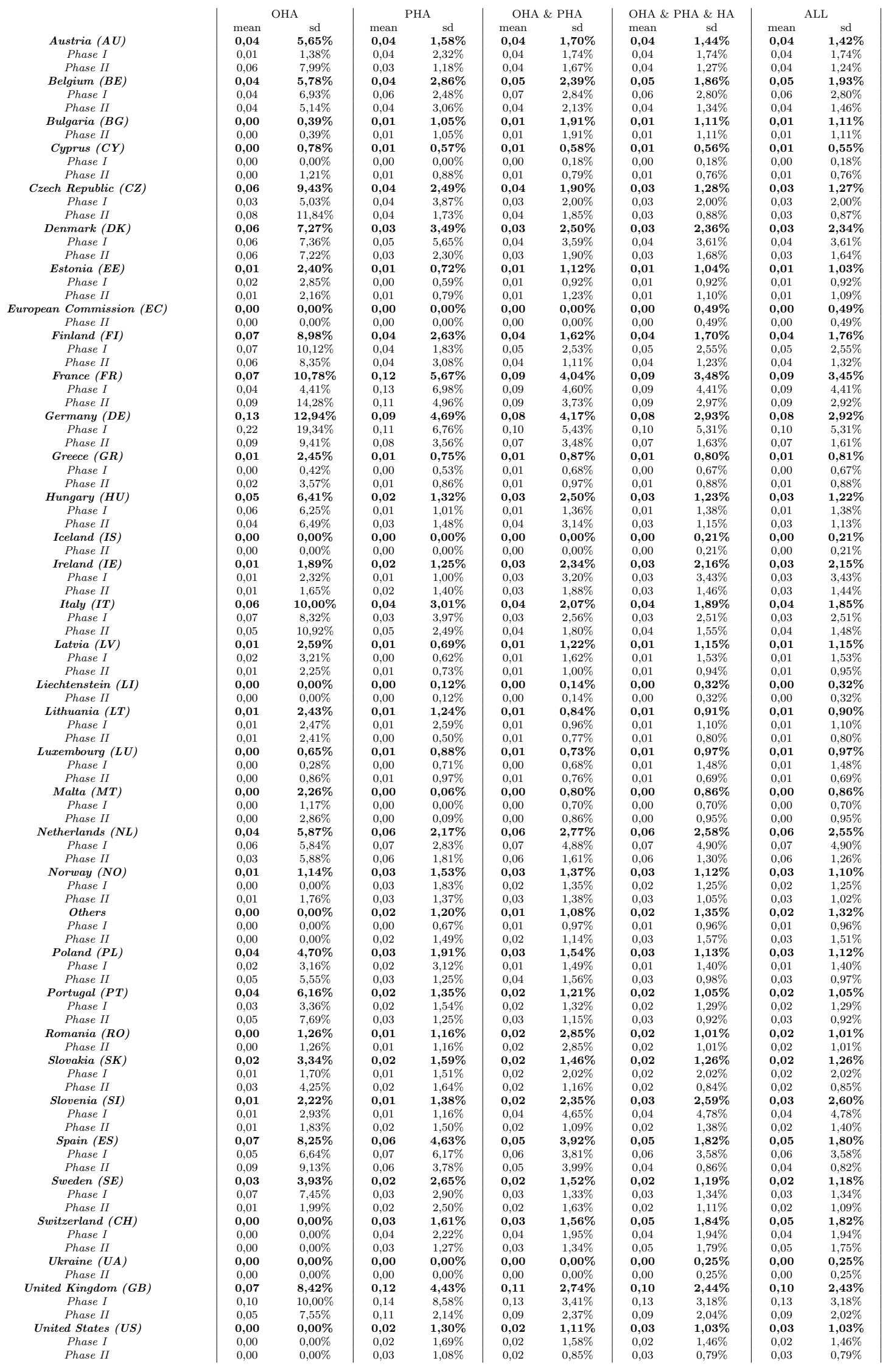




\section{A.10 Comparisons between PageRanks and number of acquiring accounts}

Figure 13: Comparisons between PageRanks and number of acquiring accounts. Plots show the correlations between PageRanks and the number of acquiring accounts; plots refer to Phase I and II, respectively. PageRanks refer to mean values from Table 3 , column ALL. Source: authors' own elaborations based on the EEA and the EUTL transactions data sets for the first two Phases.
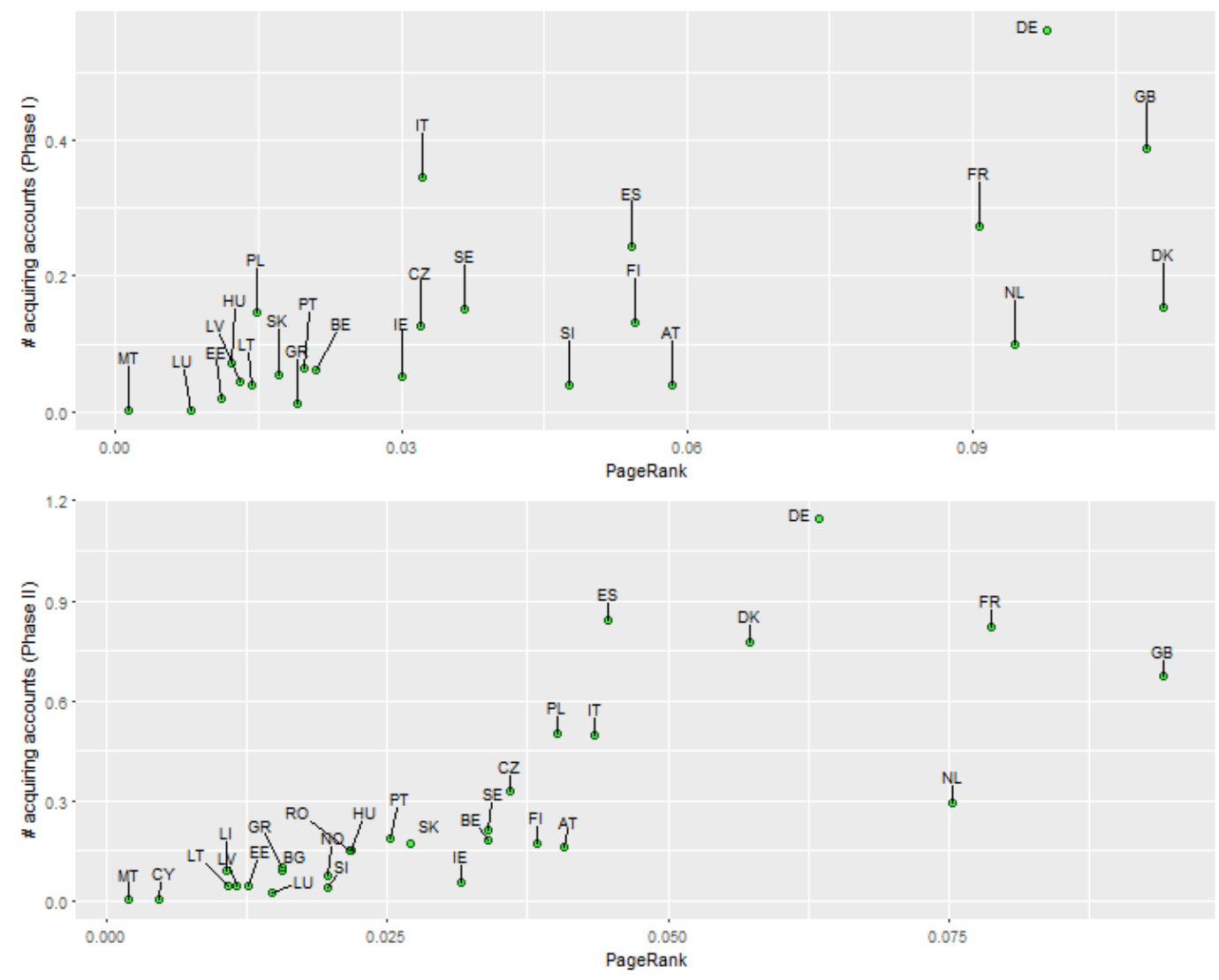


\section{A.11 EUTL network representation under Phase I and Phase II}

Figure 14: EU ETS network: transactions between OHAs and PHAs under Phase I. Data refer to transferred allowances from Apr-2005 to Dec-2007 with transaction type codes equal to 3-0, 3-21, and 10-0. The size of the node is proportional to the In-Strength, while the colour is based on the PageRank of the node and it ranges from blue (lower values) to red (higher values). Networks are drawn not oriented for representativity purposes. Source: authors' own elaborations based on the EUTL transactions data set.

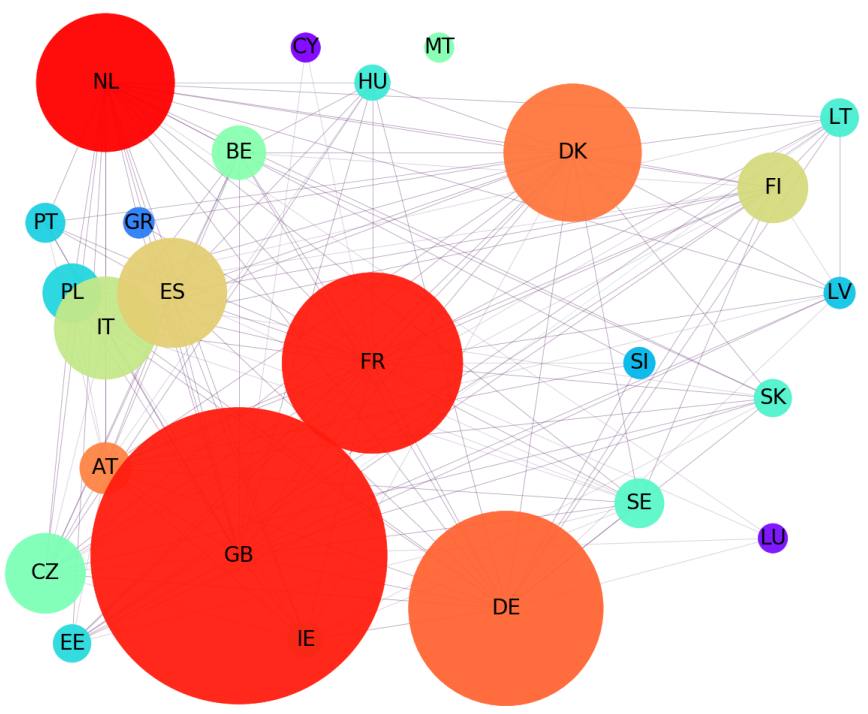

Figure 15: EU ETS network: transactions between OHAs and PHAs under Phase II. Data refer to transferred allowances from Jan-2008 to Dec-2012 with transaction type codes equal to 3-0,3-21, and 10-0. The size of the node is proportional to the In-Strength, while the colour is based on the PageRank of the node and it ranges from blue (lower values) to red (higher values). Networks are drawn not oriented for representativity purposes. Source: authors' own elaborations based on the EUTL transactions data set.

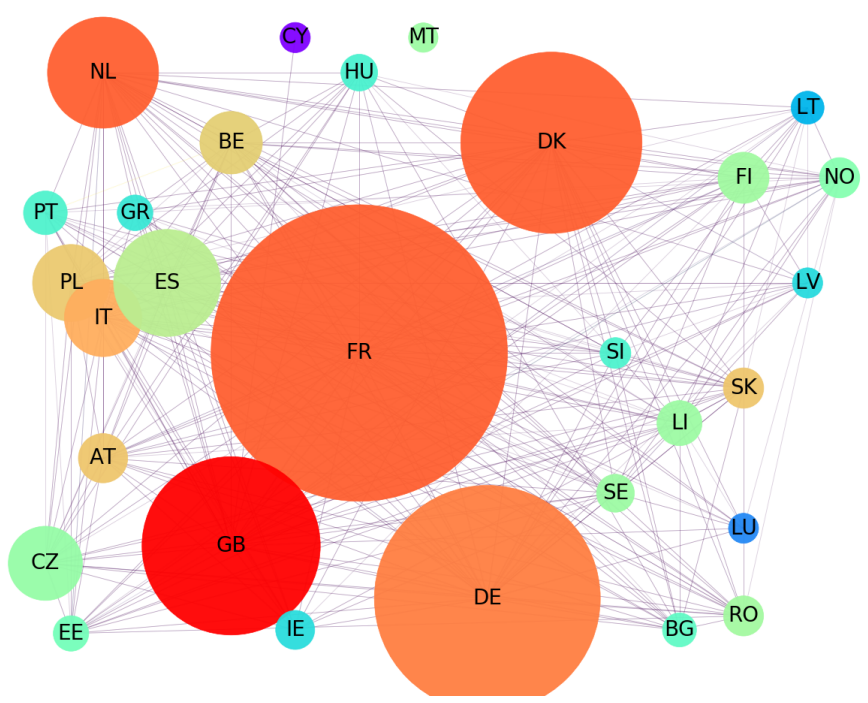

